\title{
MARTE: Technology Development and Lessons Learned from a Mars Drilling Mission Simulation
}

${ }^{1}$ Howard N. Cannon, ${ }^{1}$ Carol R. Stoker, ${ }^{1}$ Stephen E. Dunagan, ${ }^{4}$ Kiel Davis, ${ }^{3}$ Javier Gómez-Elvira, ${ }^{1}$ Brian J. Glass, ${ }^{1}$ Lawrence G. Lemke, ${ }^{2}$ David Miller, ${ }^{1}$ Rosalba Bonaccorsi, ${ }^{1}$ Mark Branson, ${ }^{1}$ Scott Christa, ${ }^{3}$ José Antonio Rodríguez-Manfredi, ${ }^{4}$ Erik Mumm, ${ }^{4}$ Gale Paulsen, ${ }^{2}$ Matt Roman, ${ }^{2}$ Alois Winterholler, ${ }^{1}$ Jhony R. Zavaleta

${ }^{1}$ NASA Ames Research Center

${ }^{2}$ School of Aerospace \& Mechanical Engineering, University of Oklahoma

${ }^{3}$ Centro de Astrobiología, CSIC/INTA, Spain

${ }^{4}$ Honeybee Robotics Spacecraft Mechanisms Corp.

The NASA Mars Astrobiology Research and Technology Experiment (MARTE) performed a field test simulating a robotic drilling mission on Mars in September, 2005. The experiment took place in Minas de Riotinto in southwestern Spain, a highly relevant Mars analog site. The experiment utilized a 10 meter class dry auger coring drill, a robotic core sample handling system, onboard science and life detection instruments, and a borehole inspection probe, all of which were mounted to a simulated lander platform. Much of the operation of the system was automated, and the resulting data was transmitted via satellite to remote science teams for analysis. The science team used the data to characterize the subsurface geology and to search for signs of life. Based on the data being received and operational constraints, the science team also directed the daily operation of the equipment. This experiment represents an important first step in understanding the technology and operational requirements for a future Mars drilling mission. In the past there have been numerous rover field tests that have helped guide the design and implementation of the highly successful rover missions to Mars. However a drilling mission potentially adds a new level of complexity, and it is important to understand the associated challenges. This paper documents the design of the experimental system, highlighting some of the more important design criteria and design trades. It also discusses the results of the field testing, and lists some of the key technological lessons learned.

\section{Introduction:}

Most familiar life forms on Earth live in the surface biosphere where liquid water, sunlight, and the essential chemical elements for life are abundant. However, such environments are not found on Mars or anywhere else in the solar system. On Mars, the surface environmental conditions of pressure and temperature prevent formation of liquid water. Furthermore, conditions at the Martian surface are unfavorable to life due to intense ultraviolet radiation and strong oxidizing compounds that destroy organic compounds. Therefore in order to search for life on Mars, it may be necessary to drill to the depth of liquid water with instrumentation to detect in situ organisms and biomarker compounds.

Searching for life in the subsurface of another planet will require drilling, sample extraction and handling, and new technologies to find and identify biomarker compounds and search for living 
organisms. Unlike rover missions, with a relatively rich history of field testing and flight heritage (Arvidson et al., 1998; 2000; Cabrol et al., 2001a; 2001b; Christian et al., 1997; Miller et al., 1992; Stoker et al., 2001; 2002; Volpe et al., 2000), these technologies have not been demonstrated in an automated system or been the subject of a mission or field mission simulation. However, the scientific community has recognized the importance of drilling and has called for it in the Mars Exploration Program Analysis Group (MEPAG) strategic plan and the NASA Astrobiology Roadmap (Des Marais et al., 2003). Thus, there is a critical need for technology maturation for drilling.

The "Mars Astrobiology Research and Technology Experiment (MARTE)" was a three year project started in 2002 and funded primarily through the NASA "Astrobiology Science and Technology for Exploring the Planets (ASTEP)" program (Stoker et al., 2007). The project had both science and technology development goals. The science goals were aimed at discovering and characterizing a Mars relevant subsurface chemoautotrophic biosphere in southwestern Spain (Minas de Riotinto) that utilizes iron and sulfide minerals as energy sources. To accomplish this goal, commercially available core drilling equipment was used to obtain water and rock samples, which were subsequently analyzed in a laboratory environment for microorganisms. This effort took place during the first two years of the project, and yielded the discovery of a complex, multi-level subsurface biological system (Stoker et al., 2004; 2005).

The technology goals of the project were to develop and demonstrate a technical approach for drilling into the Martian subsurface to search for life. In order to accomplish this, the project designed and implemented a robotic drilling and life detection platform. The design of this system was inspired by the equipment and processes utilized in the science experiment. The system was designed and developed during the first two years of the project, and then integrated and deployed in the third year. The system was tested for two weeks in a limestone quarry near Santa Cruz, California, and then deployed and used in a month long drill mission simulation that took place at an abandoned mine site in Peña Del Hierro, near Minas de Riotinto, Spain. The Rio Tinto (Red River) region was selected because it is proving to be a highly relevant Mars analog site (Fairén et al., 2004; Squyres et al., 2004). 


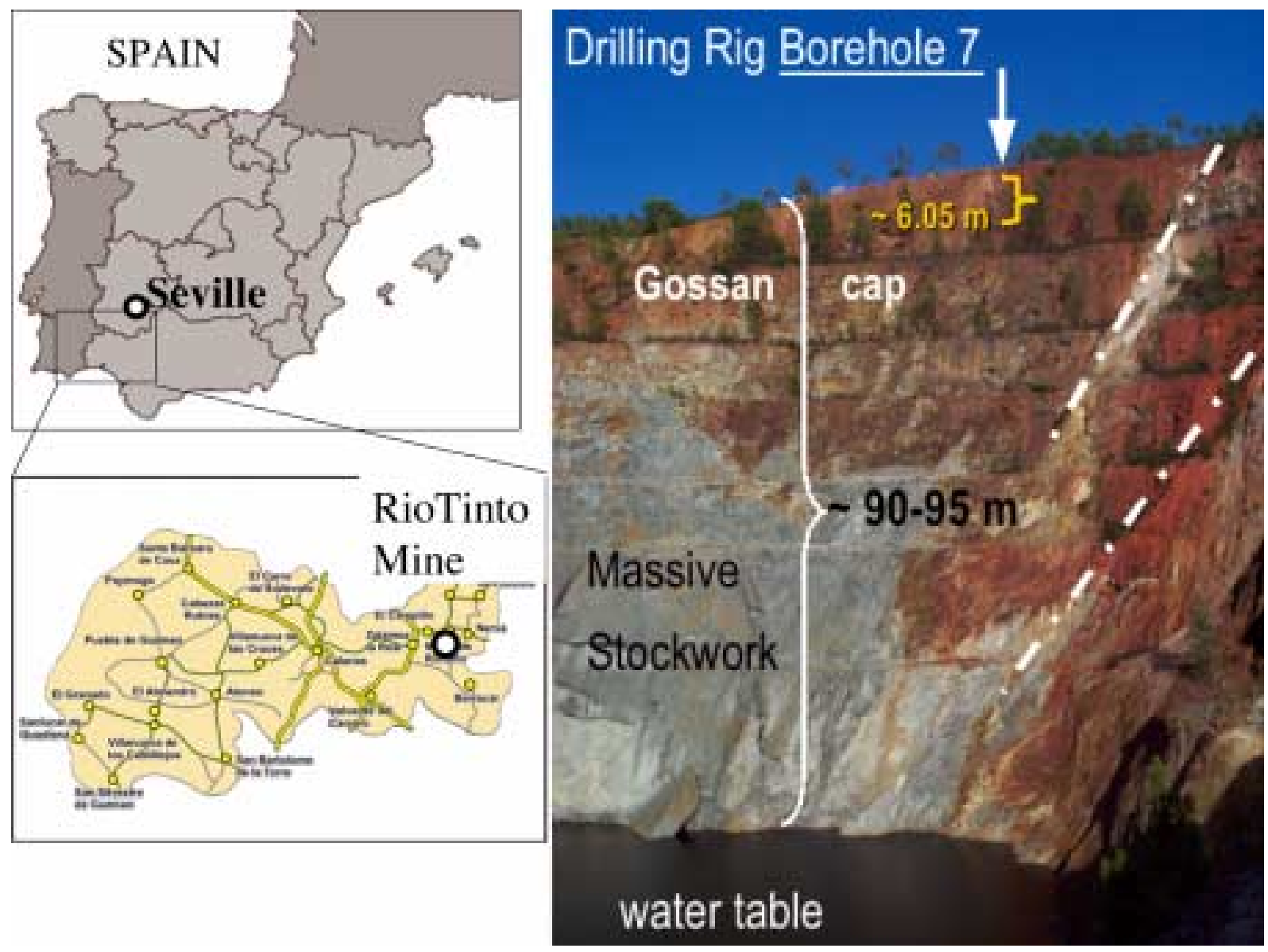

Figure 1: The MARTE Field Experiment took place in a mine site in Peña Del Heirro, near Minas de Riotinto, Spain. In the experiment, a robotic drill system penetrated approximately 6.05 meters into the Gossan cap in order to simulate a Mars drilling mission.

During the entire drill mission simulation, remote science teams in the US and Spain directed the operation of the robotic drill system by submitting daily operational plans. These plans were encoded into a procedural language used by the onboard automation system, which then executed the tasks that were requested by the science team. The resulting data was then transferred back to the science team at the end of each day via satellite for analysis and subsequent planning. Communication between the engineers supporting the equipment at the drill site and the scientists was restricted through an operations manager. These communications were conducted in such a way as to preserve from the scientists' perspective that they were working on an actual mission on Mars. 
The success criteria for the drill mission simulation were to achieve at least 5 meters of drill depth, obtain sufficient core data to describe the geologic formation, and obtain at least one positive and substantiated life detection signature. All success criteria were met or exceeded. This paper describes the design of the robotic drilling and life detection system for the technology development portion of the MARTE experiment. It also describes the results from the mission simulation field test, and discusses some of the lessons learned.

\section{System Description:}

Figure 2 shows the overall MARTE robotic system used to simulate a Mars drilling mission. The platform is a fully automated and integrated drilling, sample processing, sample characterization, and life detection platform. The system can be subdivided into six primary subsystems:

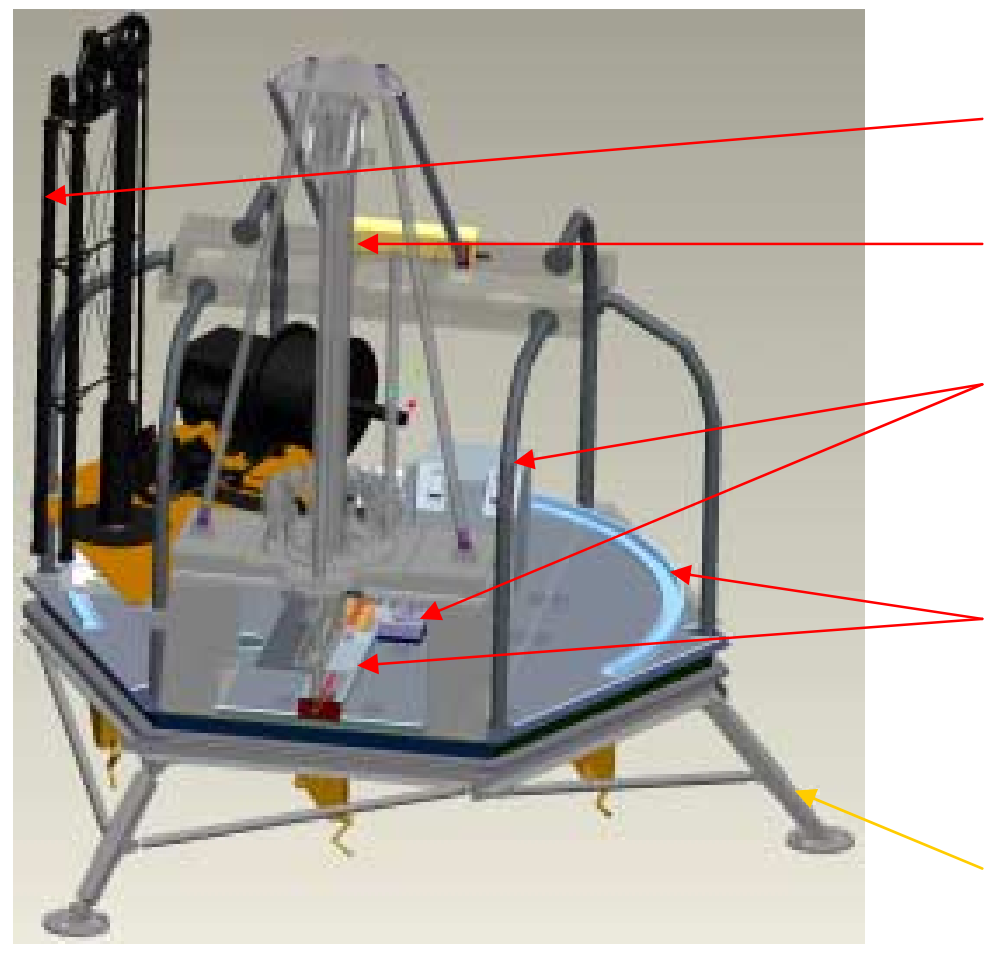

\section{Borehole Inspection System (BHIS)}

Drill Subsystem

Remote Science and Life Detection Instruments

Core Sample Handling System (CSHS)

\section{Drill Core \& Service Module (DCSM)}

Figure 2: Overview of the MARTE robotic system. The entire system is approximately 3 meters tall by 2.4 meters in diameter.

The Drill Subsystem, developed by Honeybee Robotics, is an automated, low power (150Watt), 10axis, deep drill and core retrieval system. It is designed for dry subsurface sample recovery down to 10 meters. The drill system produces a $27 \mathrm{~mm}$ x $250 \mathrm{~mm}$ core which is robotically handed-off to the Core \& Sample Handling System (CSHS) for processing and analysis.

The Core \& Sample Handling System (CSHS) is an automated sample handling and preparation system developed by the University of Oklahoma. It receives the core from the drill system into a multi-jaw core clamp, and then prepares the core by sawing it open to expose an uncontaminated surface. Using a linear rail, the core is run past a suite of Remote Science Instruments (RSI) for data collection, and then stored. Up to 9 cores can be stored at one time. Later, the science team may 
decide to pull a core from storage to repeat measurements, subsample the core, or eject it from storage. For subsampling the CSHS uses a double bladed saw to obtain a sample, uses a low power rock crusher for turning the sample into powder, and then deposits the powder into the life detection instrument.

The Remote Science Instruments (RSI) consist of remotely operable surface analysis and recording instruments, that provide visual and analytical data of the processed core. The RSI suite is made up of commercially available high resolution context and microscopic cameras, a VIS-NIR spectrometer, and a hyper-spectral imager developed by NASA Ames, and an MVP ATP Luminometer.

The Life Detection Instruments are used to detect and classify signatures of past or present life. The Signs Of Life Detector (SOLID) developed by the Centro de Astrobiología from the Spanish Aerospace Technology National Institute, is a portable automated instrument that uses protein microarray technologies to detect organic compounds. On a Mars mission, the number of analysis chambers within SOLID will be limited due to mass and volume considerations. To make the simulation more realistic, the science team was restricted to testing less than 24 samples. Thus the science team had to pre-screen potential samples using the RSI, as well as decide on appropriate strategies for utilizing this consumable resource.

The Bore Hole Inspection System (BHIS), also developed by the Centro de Astrobiología, contains two probes that are lowered into the borehole to collect in-situ data about the side walls of the hole. The first probe called a Borehole Inspection Tool (BHIT) includes a Raman spectrometer and microscopic imager. The second probe is a commercially available probe for measuring magnetic susceptibility. An automated tether/reel mechanism is used to raise and lower the probes into the hole.

The Drill Core \& Service Module (DCSM) is the rigid, vibration-isolated structural platform that supports all the other components and provides them with the electrical power, communications capabilities, and mechanical capabilities to have simultaneous drilling and core analysis operations. The top deck of the DCSM rotates, thus enabling either the Drill or BHIS to access to the borehole as needed.

The Remote Operation and Automation Subsystem is responsible for controlling each subsystem to perform its task based on a prescribed plan generated by the science team. Likewise, the system is responsible for collecting, transmitting, displaying, and archiving the science and engineering data for the science team.

\section{Subsystem Descriptions:}

\subsection{Drill Subsystem}

Honeybee Robotics' MARTE drill is a highly automated deep drill and core retrieval system (Paulsen et al., 2006). The 10-axis system is designed for subsurface sample recovery and hand-off from depths of up to 10 meters. For project risk mitigation reasons, the nominal core and borehole diameter dimensions were chosen to be compatible with AQ series terrestrial diamond coring systems. The MARTE drill, Figure 3, produces rock cores $27 \mathrm{~mm}$ in diameter and $250 \mathrm{~mm}$ long while creating a $48 \mathrm{~mm}$ diameter borehole. The drilling mechanism utilizes dry rotary cutting techniques including both carbide drag cutters and mono-crystal diamonds. A core hand-off subsystem removes the acquired core from the lead drill tube and delivers it to a core clamp in the 
CSHS for sample preparation and delivery to scientific instruments on the MARTE lander. The system is designed to operate at or below an average power of 150 Watts during nominal drilling operations. Highly integrated sensor feedback control on all drilling axes allows for future integration of intelligent drilling algorithms and fully autonomous operation.

Drilling Mechanisms: The drill system has 7 degrees of freedom. The auger axis rotates the drill bit, the $\mathrm{z}$ axis provides weight on bit and bit penetration, the drill head and drill string actuators lock and unlock drill segments, the index axis locates the drill segment feeder beneath the drill head to add or subtract a drill segment from the borehole, the core break-off axis captures and retains cores in the borehole, and the clamp holds drill segments in place during add/subtract operations.

The drill is capable of drilling 10 meters below the surface. The 1.5 meter lead drill segment is followed by 10 identical 1 meter drill segments. The drill segments are added to the drill string when the drill head approaches the lower limit of the z-axis. When a core is brought to the surface, each drill segment is stored in the index cache as the core is pulled from the bore-hole. Addition and subtraction of the drill segments during drilling and core retrieval is done autonomously.

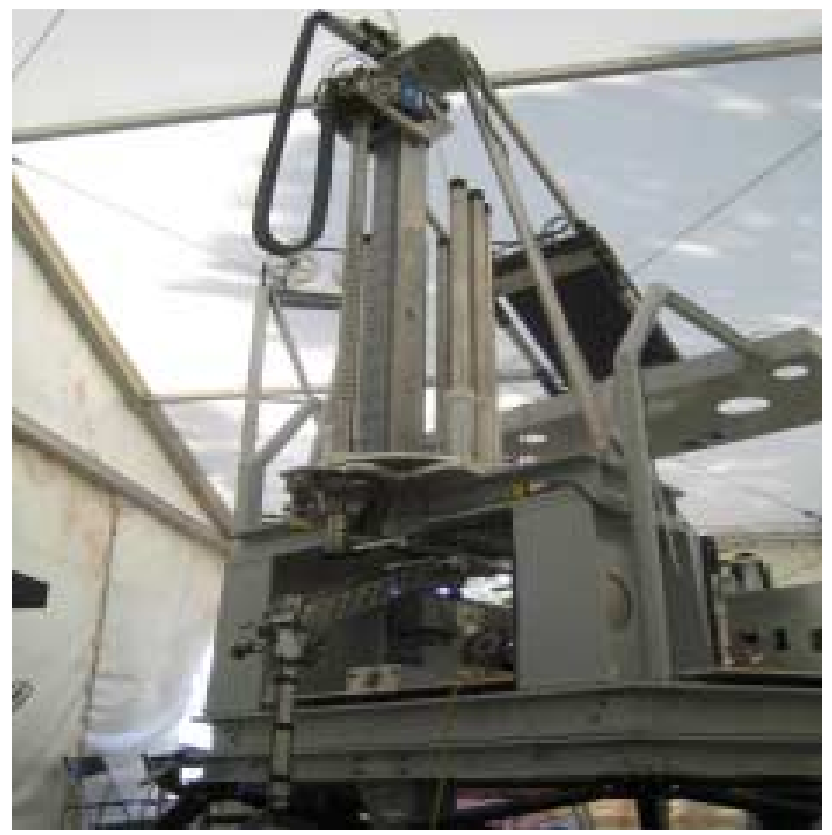

Figure 3: The Drill Subsystem with lead drill string and coring bit attached. The drill system also includes a rotating cache with additional drill strings, and a Drill Core Hand-Off Mechanism.

The drill utilizes dry rotary cutting techniques to penetrate. Extensive lab testing on Gossan and Volcanic Sedimentary rocks from de Peña del Hierro mining site led to two types of drill bit designs. Depending on the properties of the subsurface target, carbide drag cutters or surface-set monocrystal diamond coring bits are used. To start a bore-hole on unpredictable terrain, a full faced carbide cutter is used to drill the first few centimeters and establish a stable borehole for the coring bits. Compressive strength, moisture content, grain size, mineral content, and many more rock characteristics contribute to selecting the appropriate drill bit for a given section of the borehole.

The coring bits are open at the center in order to produce the core. As the drill penetrates, the uncut core material at the center of the bit is pushed into a round, hollow tube located in the lead drill stem, called the core barrel. When the core barrel is filled, a mechanism inside the drill stem rotates the 
core barrel, thus imparting a bending stress on the core. This breaks the core from the ground, which is then subsequently carried to the surface by raising the drill.

A continuous coring approach was desired by the science team, and therefore established in the mission requirements. Every 25 centimeters a core is pulled from the borehole and delivered to the CSHS. To maximize the efficiency of the drill given continuous coring operational scenarios, cuttings are collected in the lead drill segment and brought to the surface with each core. Drill cuttings are augured up the first 1.5 meters above the drill bit where they are collected inside the lead drill segment. This approach minimizes parasitic torque and weight on bit losses in the hole due to cuttings transport.

Drill Core Hand-Off Mechanism: A three axis core hand-off system interfaces with the drill system to accept a core and place it in the CSHS core clamp. The core hand-off subsystem positions itself beneath the drill bit, opens its gripper and accepts the core barrel from the lead drill segment. Once the core barrel is released from the lead drill segment, a synchronized sequence places the core into the CSHS clamp. The sequence consists of first rotating the barrel so that it is aligned with the clamp, and then pushing the core out of the barrel with an internal plunger into the clamp.

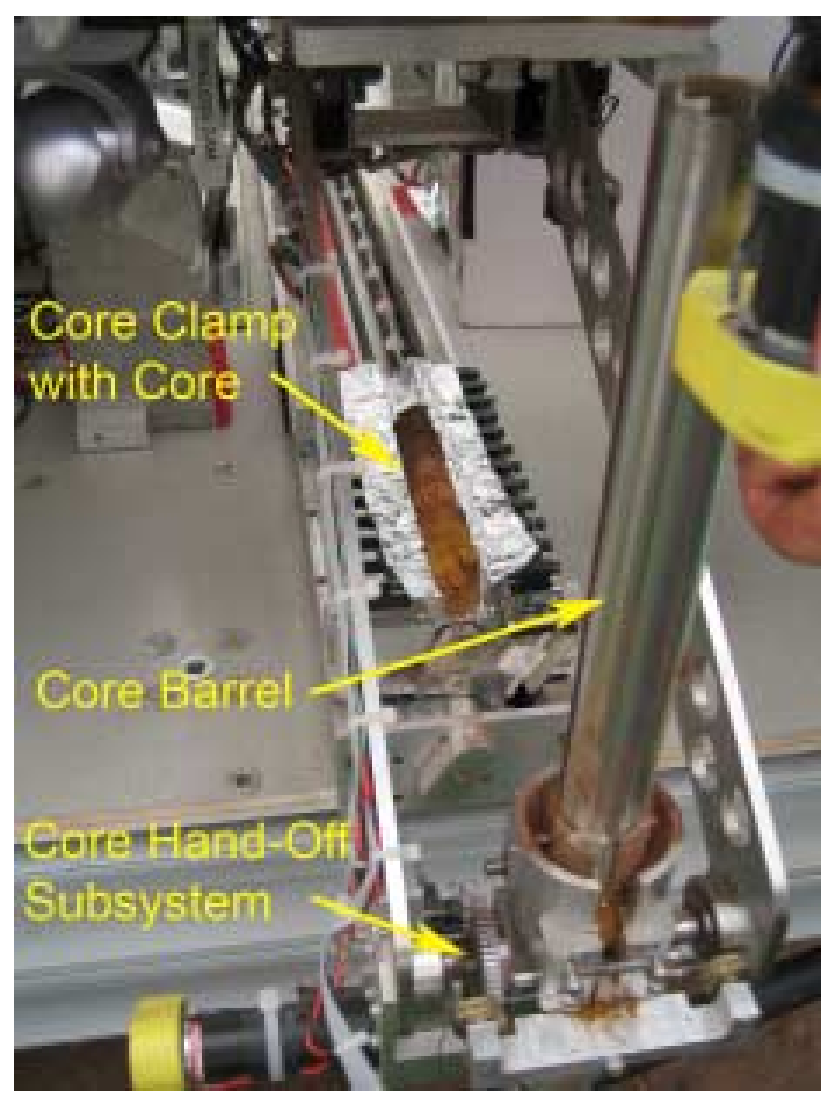

Figure 4: The Core Hand-Off Mechanism places the core into the CSHS clamp.

The most important design driver in the development of the core hand-off system was to maintain the integrity of the core sample in order to maximize the scientific return from the remote sensing instruments. The translate and plunger axes of the core hand-off system run in opposite directions at 
equal speed resulting in zero relative velocity of the core sample as it is placed in the clamp. The stratigraphy of the core sample is maintained via this method. The core is placed in the core clamp exactly as it was taken from the subsurface.

Drill Control System: The auger, drill head, $\mathrm{z}$ axis, drill string, index axis, Core Hand-Off actuators, and clamp axes are instrumented with optical encoders for position and velocity control. The break-off axis utilizes an imbedded linear potentiometer for absolute position feedback of the core break-off mechanism within the lead drill segment. Electrical current sensing is available for all actuators except drill head, drill string, and break-off motors. Weight on bit is derived via a tension/compression load cell located inline with the $\mathrm{z}$-axis ball screw. The load cell is also used to automate addition and subtraction of drill segments to the borehole, utilizing a drill string connection mechanism. Each drill segment passes 9 power or signal channels through the connection mechanism to drive the drill string motors and core break-off actuator located in the lead drill string. Thus, power and data may be run through all drill segments to the bottom of the hole.

An onboard computer is responsible for the control of all of the drill mechanisms. A hierarchical set of commands and parameter settings for the control may be issued manually through a remote user interface, or commanded via the Executive in the Remote Operations and Automation Subsystem. For example, high level automated commands are provided for traversing down hole and touching the bottom, breaking the core, returning to the top of hole, and transferring the core. In addition, low level commands can be sent to move each individual axis, or adjust parameters such as gains and offsets.

\subsection{Core Sample Handling Subsystem}

The Core Sample Handling System (CSHS) consists of several robotic devices (Winterholler et al., 2005). The CSHS receives a core from the drill system into the Core Clamp which is a 24 DoF gripper designed to hold tightly onto a core which can be anything from a $27 \mathrm{~mm}$ diameter $250 \mathrm{~mm}$ length rod of solid rock, to a pile of chips and gravel. The clamp/core is run under a Facing Saw; whose feed rate is autonomously adjusted by the required cutting force for the material at hand. The faced sample is then run under a set of remote science instruments. Finally the clamp/core is placed into a random access storage system capable of storing $2.25 \mathrm{~m}$ of core. This storage provides the science team with time to analyze data and decide which cores, if any, should be subjected to subsampling for biological analysis. If sub-sampling is desired, then the effected core is brought out of storage, and an $18 \mathrm{~mm}$ segment of the core surrounding the spot of science interest is removed by the Sub-sampling Saw. This small piece of core is then crushed to powder, sifted, and inserted into the SOLID life detection instrument. Each of these devices is described in more detail below.

Core Clamps: The CSHS is equipped with nine Core Clamps. The Core Clamps serve as fixtures for the retrieved subsurface core samples. The Core Clamps hold the core during sample preparation, and maintain a defined position while the different scientific instruments examine it. 


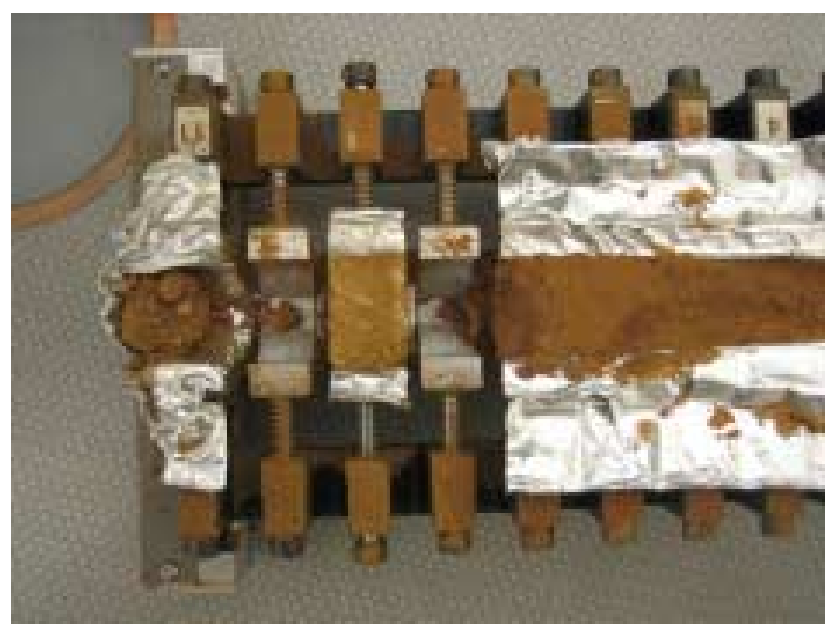

Figure 5: CSHS Core Clamp holding the core after subsampling. The subsample is still held by the third jaw.

The core sample is transferred and placed into the Core Clamp by the Drill's Core Hand-Off Mechanism. A motor mounted to the Linear Rail Cart closes and opens the Core Clamp. The Core Clamp is symmetric to the longitudinal axis. Each side consists of a bar which holds 12 jaws. The ends of the bar are supported by threaded shafts. The four threaded shafts are simultaneously driven by a central drive shaft. The clamping force is applied to the sample with the concave shaped jaws. The individual spring loaded jaws comply with irregular shaped and fractured samples. This assures a good grip on the core even if it is fragmented. In addition, the spaces between the jaws enable the Sub-sampling System to cut through and remove a disc shaped sub-sample. The bottom side of the Core Clamp incorporates a locking mechanism that provides a rigid connection while the Core Clamp is on the Linear Rail Cart.

Linear Rail \& Cart: The rail mechanism is responsible for positioning the clamp/core at each station along its $2 \mathrm{~m}$ length where sample preparation or remote sensing can be done. The rail must feed the samples into the Facing Saw slow enough to allow the top of the rock to be removed without stalling or damaging the saw. The scanning speed under the spectrometer is also critical to obtaining good data. These speeds are on the order of 0.01 to $0.1 \mathrm{~mm} / \mathrm{s}$. A twin motor design is used to accomplish these low speeds as well as a much higher speed to decrease the time spent moving between stations. The higher speed can move the core from one end of the rail to the other in approximately 5 minutes. This speed is needed to keep core processing in sequence with the drill. 


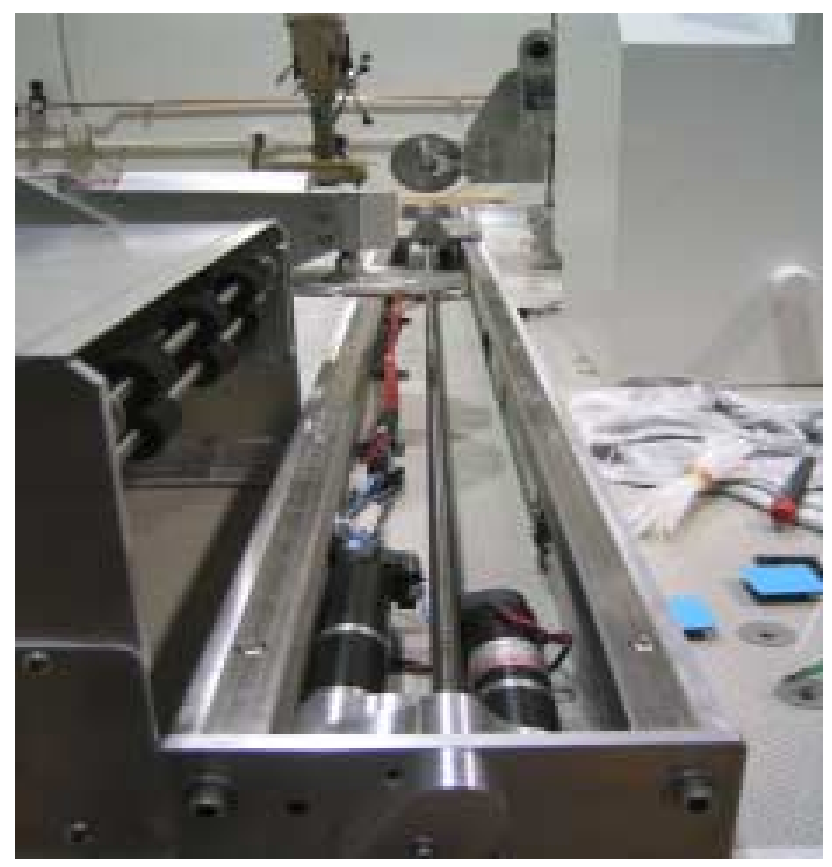

Figure 6: CSHS Linear Rail. The linear rail transports the clamp and core beneath instruments and the facing and subsampling saws.

Each Core Clamp is translated between stations and actuated by the cart. The under side of the cart includes a mechanism to open and close the clamp and a mechanism to release the clamp from the Cart. The two sides of the cart have elevated rails that guide the cart into position when being loaded from the Core Storage System and hold the clamp in place during sub-sampling and facing operations.

Core Storage: The Core Storage System provides the capability to hold up to nine core samples and retrieve them later for further analysis. In addition, the Core Storage System is used to dispose of core samples after scientific investigations are completed. The Core Storage System consists of two main components: a stationary Circular Rail and a rotating Storage Comb. The circular shape was employed to most effectively fit on to the hexagonal lander platform. The Circular Rail spans about two thirds of a full circle and is mounted to the DCSM. The Storage Comb rides along the Circular rail, thus enabling transfer of the clamp between any set of forks in the comb and the Linear Rail Cart. 


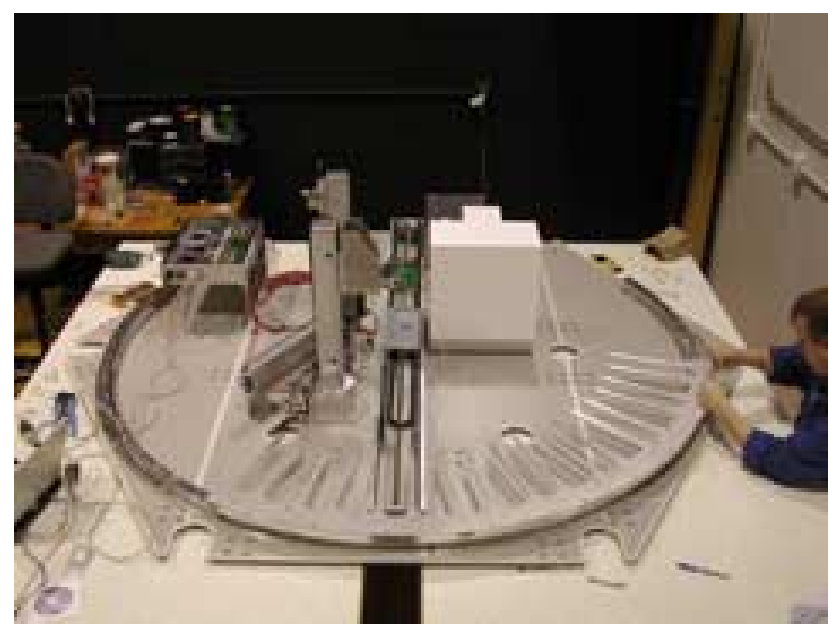

Figure 7: CSHS Core Storage System. The Core Storage System holds the cores until the scientists decide to either subsample or discard them.

The Storage Comb holds a maximum of nine Core Clamps during nominal operation. In order to perform clamp swap and core disposal operations, one clamp storage spot has to be empty. A Core Clamp exchange is performed by unlocking the Core Clamp from the Linear Rail Cart and simultaneously locking it to the Core Storage System. The Linear Rail Cart is then pulled out from underneath while the Core Clamp stays on the Storage Comb. The sequence to eject an uninteresting core sample starts with moving the Core Clamp from storage onto the Linear Rail. The Core Clamp is then opened and transferred onto a pivot-able fork at the counterclockwise end of the Storage Comb. A mechanism tilts this storage fork such that the core sample slides off the Core Clamp and falls to the ground. The Core Clamp is then available to load another core sample.

Facing Saw: The Facing Saw removes the top external surface of the acquired core along its length. This is done to achieve a clean planar surface that will be a standard height for all imaging and spectrometer readings. A dry cutting diamond encrusted masonry blade with a discontinuous circumference to allow better chip removal is lowered into position approximately $5 \mathrm{~mm}$ from the top of the Core Clamp. The clamp is then translated slowly beneath the blade to shave off the top of the core. The blade is $150 \mathrm{~mm}$ in diameter and $2.6 \mathrm{~mm}$ thick. The blade is lifted and lowered by a retraction mechanism designed into the main body of the saw. A motor and worm gear combination drives a pinion shaft that rides along a curved gear track in order to produce the rotating motion. 


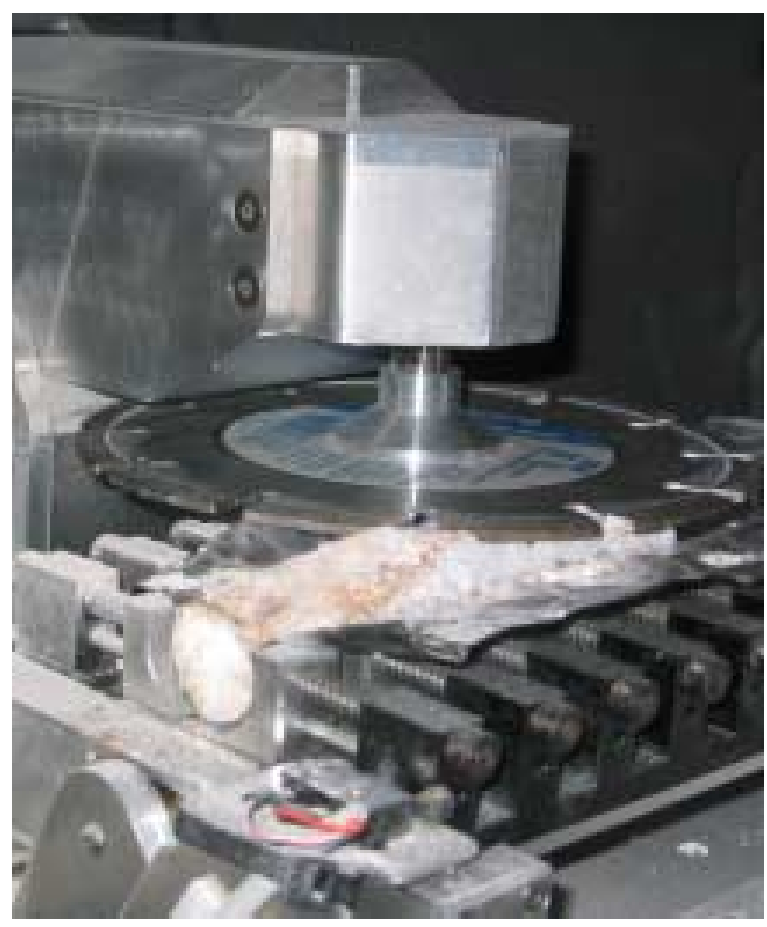

Figure 8: CSHS Facing Saw. The Facing Saw creates a clean flat surface on the top of the core for improved sensing

Sub-Sampler: Each rock sample taken by the drill is scanned by the remote sensing instruments then placed on the Storage Comb. If the data shows that a particular segment of the core is of special interest then a sub-sample of that area can be taken. The sub-sampling system uses twin saw blades parallel to each other to cut perpendicular to the axis of the core sample. The saw blades are translated vertically downward to cut through the sample. Once through the sample, the blades stop; then squeeze together to pick up the rock left between them. Both 100mm diameter blades are driven from the same motor. The blades can be opened $39 \mathrm{~mm}$ and close on a sample as narrow as $14 \mathrm{~mm}$ wide (the width of a clamp jaw), with the typical size of a sample being approximately $17 \mathrm{~mm}$.

Crushing and Sample Transfer: Once a segment from the core has been extracted by the SubSampler saw, it must be prepared for insertion into the SOLID life detection instrument. SOLID requires $0.75 \mathrm{ml}$ of powder of a grain size of $500 \mu \mathrm{m}$ or smaller. To reduce the core material to this particle size we use a miniature rock crusher developed at the Jet Propulsion Laboratory (Hansen et al., 2007). This crusher produces particles of which only about $40 \%$ are the correct size $(0.5 \mathrm{~mm})$-the remainder being too large. To eliminate the oversized particles the CSHS employs a simple sieve. A small vibrator motor is used to help sift the particles through the sieve and onto a chute.

The chute leads down to a core transfer tube. This tube has a small funnel and some fill holes. The chute touches the funnel causing it to vibrate as well and the small rock particles stream into the funnel, through the holes and into the tube. The tube has a plug on the bottom which can be opened by pressing on a spring-loaded stem at the tube's top. A tube feeder rack holds 13 of these disposable tubes in place. When a tube is used, a motor moves the next tube into place under the crusher. 


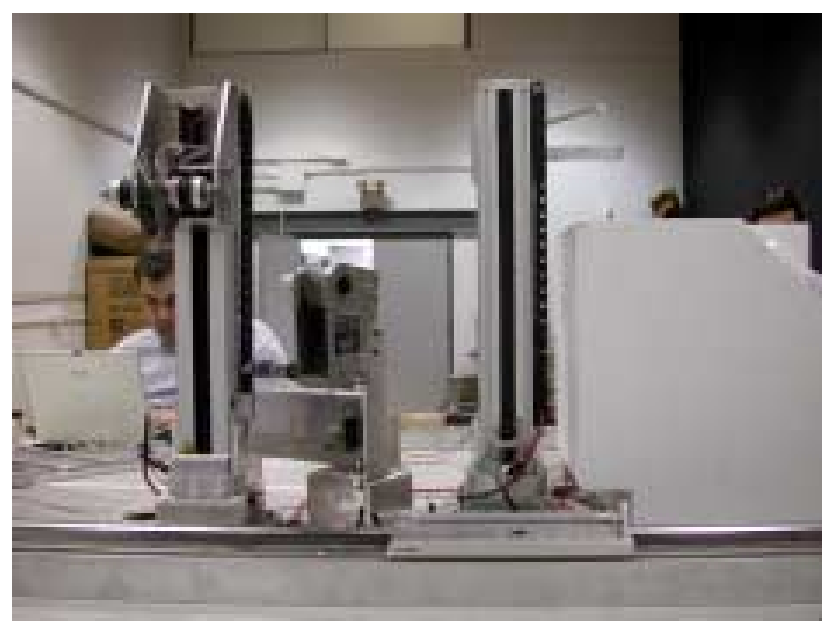

Figure 9: CSHS Mechanisms for subsample acquisition and preparation. The systems are left to right: Subsampler, Crusher, SampleTransfer Mechanism.

A Sample Transfer Mechanism is used to move the tube full of crushed rock from the tube feeder rack and insert it into SOLID. The arm is mounted on a rotational/vertical actuation base identical to the Sub-sampler. It uses a solenoid actuated opposing clamp that slides open once it moves into position to pick up a full tube. The solenoid is released and the clamp is closed by a return spring. The tube is then lifted and rotated over the SOLID instrument. When it is positioned correctly the lower half of the Sample Tube is lowered into a split-gasket-sealed opening on top of SOLID. To release the contents of the tube, a motor spins a crank that is connected to a hammer which depresses the spring loaded seal on the bottom of the tube.

CSHS Control System: The integrated system is controlled through an onboard Executive in the Remote Operations and Automation Subsystem. This in turn sends serial commands to the CSHS real-time controllers. The CSHS has 18 powered actuators and about twice that many sensors. Most of the actuators need to run under PID position control; some run under PID speed control and some operate at set PWM rates. To get high positional accuracy and repeatability, and maintain the flexibility required, we used a custom controller that was a modification of the XBC robot controller (LeGrand et al., 2005). This controller makes use of a 100K gate FPGA which handles the PID and PWM control along with the digital inputs from the sensors. The CPU and LCD screen for the controller are contained in a COTS Nintendo GBA. The FPGA board with its daughter board that contains all of the motor drivers connects through the game port slot on the GBA. This system runs through the control loop at about $200 \mathrm{~Hz}$.

\subsection{Remote Sensing Instruments}

Core Context Imager: This camera captures the full length of the $25 \mathrm{~cm}$ core segment at a resolution of about $125 \mathrm{microns} /$ pixel in color. The imager is a $3.2 \mathrm{Mpx}$ (2048x1536 pixels) Canon Power-Shot S230 with remotely operated functions (shutter release, zoom, flash, WB) via USB connection. The JPEG image file generated by the camera is about $1.6 \mathrm{Mb}$ in size. During the field experiment, one image per core was taken with this camera immediately after the facing operation. An image was acquired after subsampling as well to show the scientists what area was captured. 


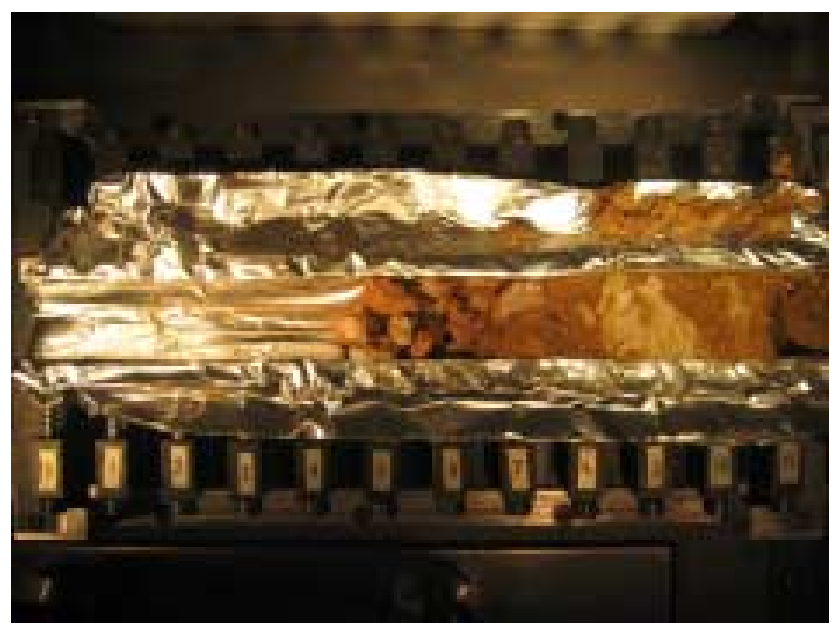

Figure 10: Image of Core 24 from the Core Context Imager. This camera provides an overall view of the core. Locations along the core are identified by the numbered labels.

Microscopic Imager: Microscopic images of the core are acquired using a Canon EOS-10D with a $100 \mathrm{~mm}$ macro-lens. This obtains color microscopic quality images of pre-determined sections of the core with about a 8 microns per pixel resolution and a field of view of $2.5 \times 1.66 \mathrm{~cm}$. The sizes of the JPEG files generated are approximately 6.7MB and transmitted via USB interface. During the mission, 6 microscopic images were taken at fixed distances along the core length. At times the scientists would request additional microscopic images at locations corresponding to interesting features.

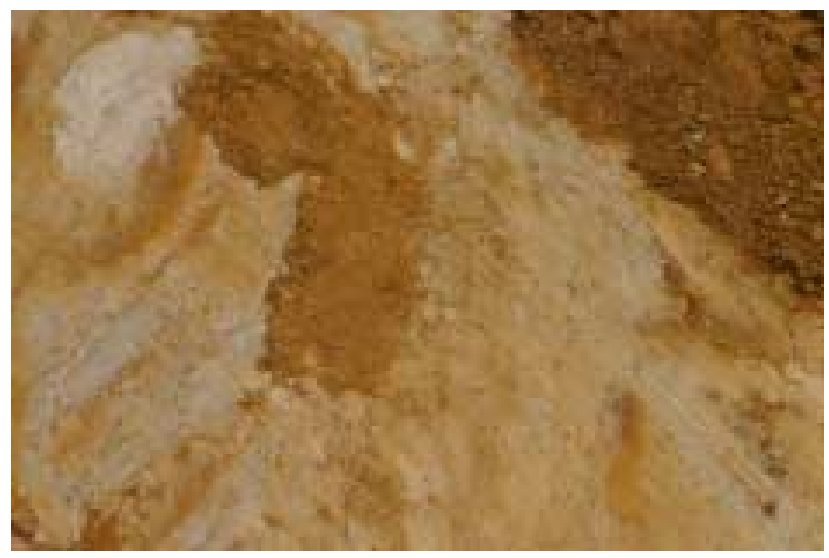

Figure 11: Microscopic image of Core 24, location 9.

Visible Near Infrared Spectrometer: The locations of the core imaged with the Microscopic Imager are also analyzed with the VNIR spectrometer. The VNIR spectrometer is an Ocean Optics S2000 Temperature Regulated Spectrometer, with a \#3 grating (range of 400nm to 1050nm) with a high-sensitivity linear CCD array (2048 element). The spectrometer system is composed of the spectrometer enclosed inside a temperature control box capable of maintaining the set temperature to within $0.1{ }^{\circ} \mathrm{C}$; an $\mathrm{A} / \mathrm{D}$ converter box with USB computer interface, and a Tungsten-Halogen illumination lamp. The reflectance probe contains six illuminating and one read fiber, all 400 
microns in diameter, UV/VIS; and is placed at an optimum distance to collect spectra of a spot $5 \mathrm{~mm}$ in diameter.

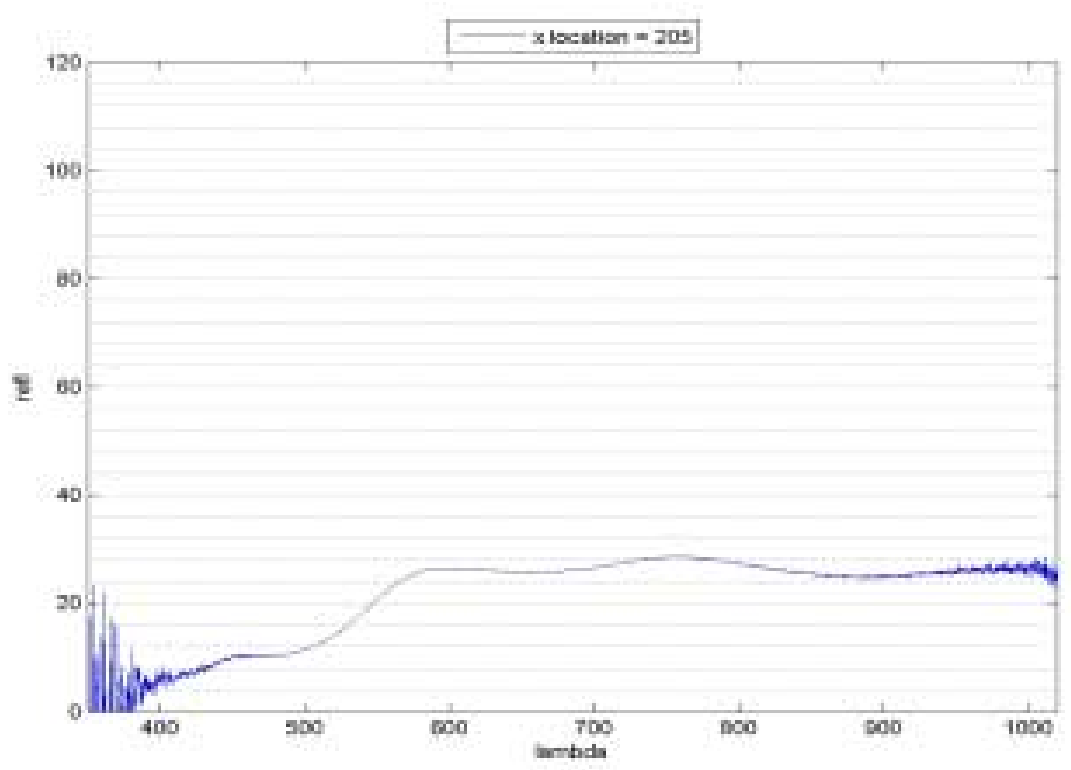

Figure 12: VNIR spectrometer results from Core 24 location 9, showing reflectance versus wavelength.

Imaging Spectrograph: The Imaging Spectrograph was developed at NASA Ames to permit highresolution imaging of rock core samples while obtaining spectral information. The instrument utilizes macroscopic imaging optics and a slit input aperture to sample a line on the object (core). A combination of dispersive and diffractive elements and relay lenses provide light to the array detector, which is separated spatially along the slit in one dimension and spectrally along the other array dimension. This is sampled with an 8-bit monochrome industrial vision CCD camera. Scanning the object in a direction normal to the slit while taking multiple images, creates a data "hyper-cube" in the mode of classic "push-broom" type remote sensing instruments (Fisher 1998; Rickard 1937). The spectrograph resolves 580 columns of 50-micron spatial elements along the input aperture. The hypercube image length is only limited by the length of the scan, presently configured for rock cores that are $25 \mathrm{~cm}$ long. The spectrum is sampled by 780 detector rows spanning the 400 to $1000 \mathrm{~nm}$ wavelength range. This over-sampled spectral data is averaged, typically over 6 rows, to improve signal quality and to reduce hypercube size. 

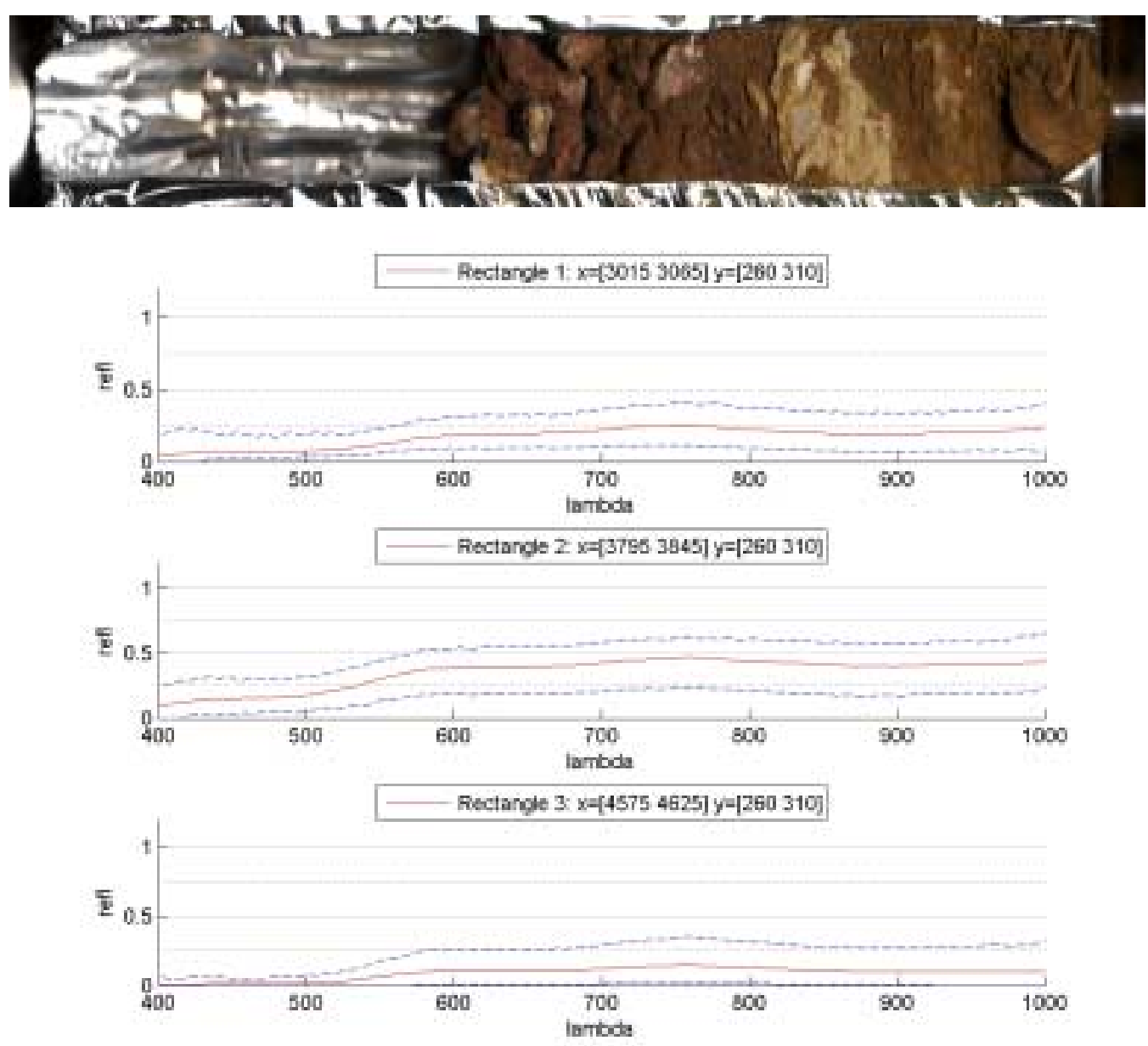

Figure 13: Top - Imaging Spectrograph RGB image for Core 24. Bottom- Spectra mined from three locations along the core. The dashed curves show max and min, while the solid curve shows the average across the pixels in the selected rectangle.

The spectrograph operates under current-controlled tungsten-halogen illumination to permit the derivation of reflectance data. A spectral calibration is performed using Krypton and Mercury-vapor emission lamps. Radiometric calibration processes include dark frame subtraction and normalization by a reference frame taken with $99 \%$ Spectralon in the object field. A "quick-look" color image is produced at the end of the scan comprised of three wavelength bands that represent normal human perception of red $(660 \mathrm{~nm})$, green $(530 \mathrm{~nm})$ and blue $(460 \mathrm{~nm})$. A scientist specifies regions of interest from the quick-look image, and sends a request to the onboard hypercube data mining software, which returns reflectance spectra data averaged over these regions. This approach removes the need to telemeter the entire hypercube and thus reduces data bandwidth. The instrument provides $\sim 48 \mathrm{~dB}$ max signal-to-noise ratio, as limited by the dynamic range of the camera and particularly limited in the short- and long-wavelength regions by the spectral response of the silicon CCD sensor and the black-body intensity distribution of the tungsten-halogen lamps. 
ATP Luminometer: The external surfaces of the cores are tested for the presence of adenosine triphosphate (ATP) via bioluminescence with the Lightning MVP instrument (manufactured by BioControl Systems Inc.) The Lightning MVP instrument uses a Luciferin-luciferase reagent to react with ATP to emit light. A cotton swab is swept across the surface of a core; then placed into a chamber where a reagent is added; then exposed to a UV light. The reagent causes fluorescence in proportion to the amount of ATP present. The reading takes about 10s and it is measured in relative light units (RLU). The MVP instrument has a sensitivity of 15 pico-grams of ATP. ATP is the energy mechanism for all living organisms so ATP luminometry is used as a screening instrument to determine the level of bacterial bioburden present on the cores. In this application it provided a "quick look" assay for the presence of bacteria in cores. The ATP Luminometer was added to the instrument suite late in the design process, and thus was not integrated with the rest of the automated onboard systems, essentially relying on manual operation.

\subsection{Life Detection Sensing}

After the scientists examine the cores using remote sensing instruments, they could select regions of the core to subsample for life detection analysis. These subsamples were cut and crushed by the CSHS Subsampling System, and deposited into the life detection instrument - the Signs of Life Detection Instrument (SOLID). SOLID is a compact portable automated instrument that uses protein microarray technologies to detect life as well as their metabolic products. The aim is to detect any kind of biochemical compound (nucleic acids, proteins, polysaccharides, etc) using microarrays printed with antibodies or any other protein or molecule able to recognize and bind specifically to them.

Molecular biology techniques allow fluorescent labeling of either the targets or the probes. A laser beam excites the sample and a CCD camera detects the bright spots. Core sections of scientific interest are sliced, powdered, and run through a series of molecular biology techniques using the SOLID instrument. SOLID performs an in-situ analysis of the core by using micro-arrays containing thousands of probes to detect organic compounds and whole cell characteristics from the powdered core samples, with a resolution better than PPB. Only 0.5 grams of powdered rock are required to conduct the procedure (Parro et. al, 2005; 2007).
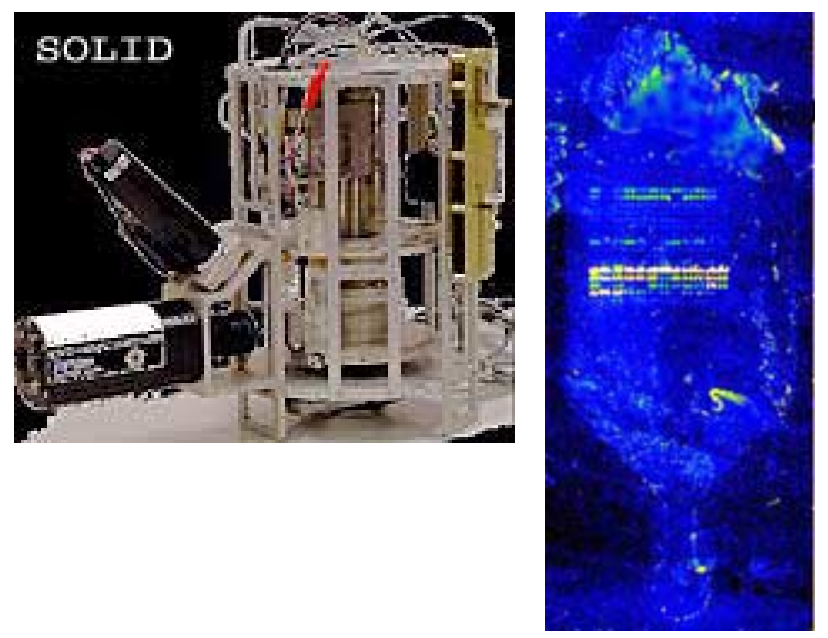

Figure 14: The SOLID life detection instrument, and the image it produces (right). Bright spots in the image indicate a positive signature. 


\subsection{Bore Hole Inspection Subsystem}

Borehole logging is a classical and standard technique used in the study of the Earth's subsurface that provides in situ measurements of the geo-physical and mineral properties of the subsoil. These values, together with the data obtained by means of the analysis of the core samples on the surface, provide meaningful and comprehensive information about the subsurface.

With this purpose, the Bore Hole Inspection System (BHIS) is devoted to inspecting the hole drilled in the surface of the Martian analog environment (Gómez-Elvira et al., 2004). The instrument was optimized to study the $48-\mathrm{mm}$ borehole as a complement to core sample analysis, being capable of performing:

- Capture of 360 degree and $12 \mathrm{~mm}$ high panoramic images of the hole walls. These images provide detailed visual information of the wall and allow geologists to get a global view under the subsoil regular conditions.

- Measurement of Raman spectra by means of a miniaturized fiber optic Raman probe placed inside the instrument and a Raman spectrometer on the surface (on the lander). This subsystem provides information about mineral paragenesis of rocks, as well as detection and determination of organic matter.

- Recording the magnetic susceptibility profile by means of a magnetic susceptibility probe in order to determine the lithological composition and to detect metallic ores.

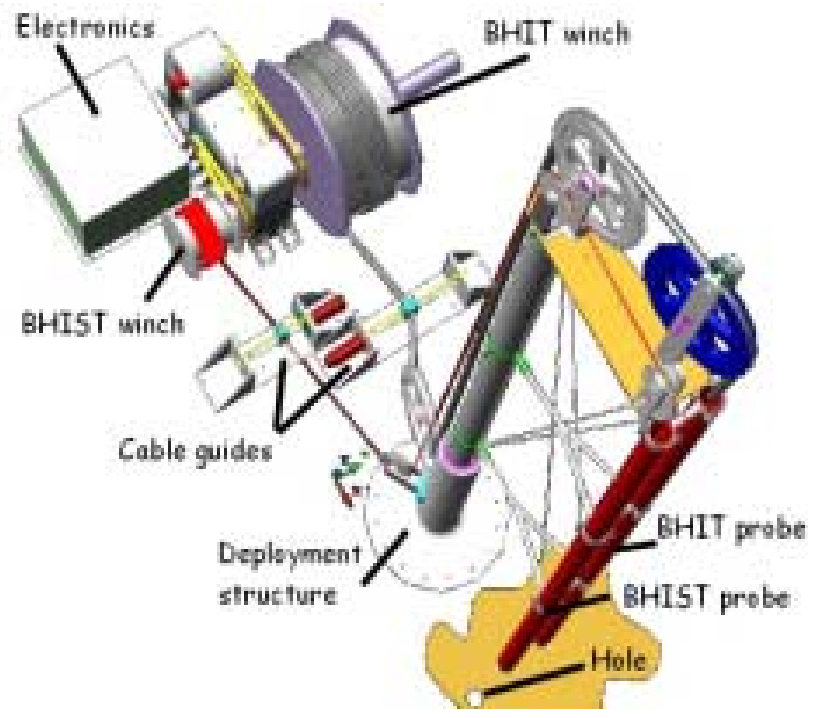

Figure 15: 3D model of the BHIS Subsystem. The BHIS includes two probes. The BHIT has a Raman spectrometer and imaging cameras. The BHIST measures magnetic susceptibility.

A custom developed probe called a Bore Hole Inspection Tool (BHIT) provides the cameras and Raman probe. An off-the-shelf subsystem called the Bore Hole Inspection Standard Tool (BHIST) provides the magnetic susceptibility measurements. The probes are located in the two tubes of the deployment structure, as shown in Figure 15. 


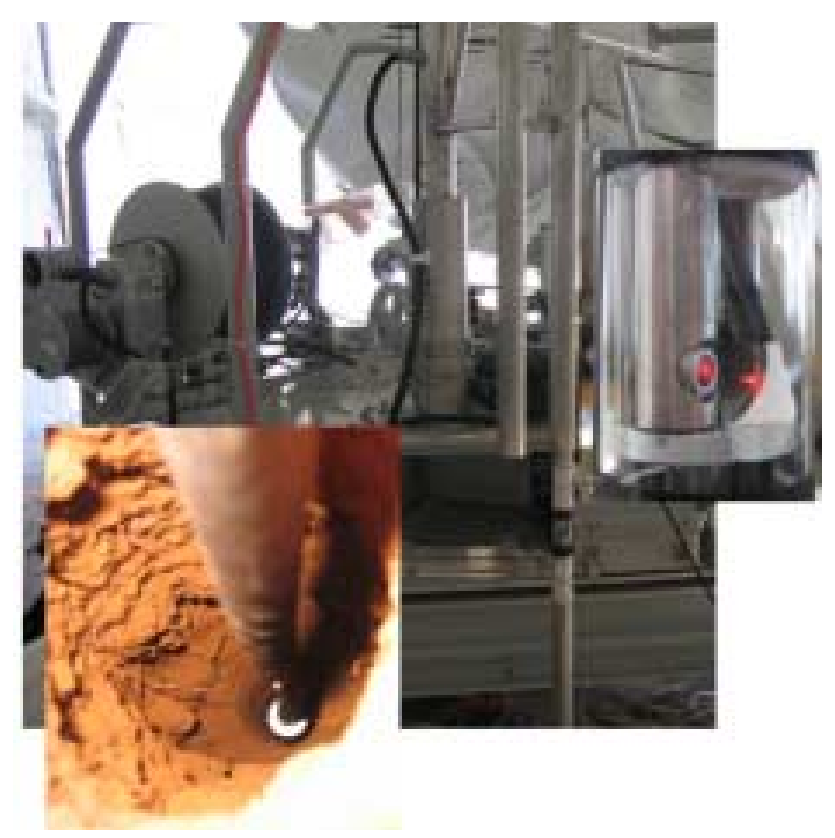

Figure 16: BHIS mounted onto the DCSM. The close-ups show the laser from the Raman probe, and how it appears down hole.

The deployment structure provides a positioning system to lower the probes to a precise depth, and to anchor the instrument to the borehole walls in order to get stable spectra and images. The precise descent is carried out by means of winch motors. In order to stabilize the instrument, rubber seals are placed along the probe's length. These seals are compressed, and in so doing, expand their external diameter to anchor the system to the borehole wall.

The subsystems to accomplish the capture of spectra and panoramic pictures are placed in two different locations: the sensor elements, inside the BHIT (such as the Raman head and the cameras), and the processing and control elements, inside the BHIT reel (such as laser, spectrometer and Raman CCD and control PC's). Both sets of elements are linked by means of electrical wires and optical fibers coiled in the BHIT reel.

\subsection{DCSM Subsystem}

The Drill Core \& Service Module (DCSM) is the simulated lander platform that supports all of the MARTE subsystems as well as the auxiliary power and computing equipment. In a flight mission, the Mars lander would provide interfaces for power, data, and mechanical mounting for the drill, core sample handling system, science instruments, and related components. The DCSM provides these same interfaces for the MARTE hardware. The DCSM was sized to fit under the shroud of a Delta II rocket. However, in order to fit within the project's allowable time and cost constraints, no attempt was made to make the DCSM "flight like" in terms of mass, volume, reliability, or style of construction. 


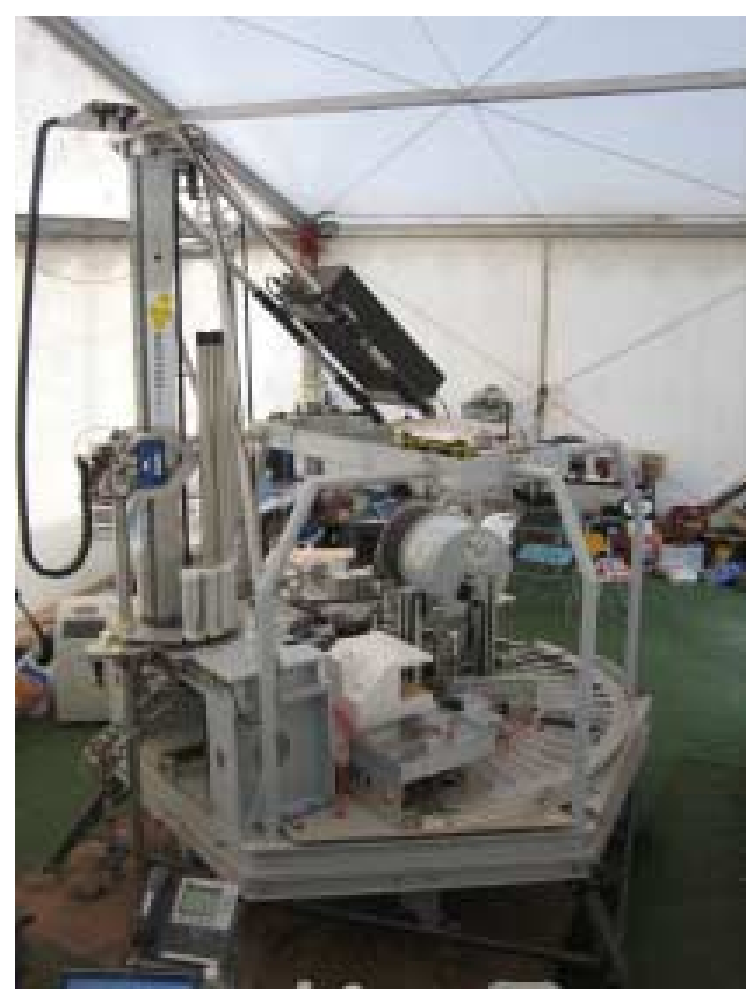

Figure 17: DCSM with mounted equipment. The DCSM consists of a 3 legged fixed base, with rotating upper structure and vibration isolation deck.

The DCSM consists of a three-legged fixed based with a rotating upper structure. Both the Drill and the BHIS are fixed rigidly to the upper structure. By rotating the upper structure, either the Drill or the BHIS can be positioned over the borehole. Since the Drill can cause significant vibration, a honeycomb vibration isolation deck was also mounted to the upper structure. The CSHS and Remote Science Instruments were mounted to this deck so that they could be operated in parallel with drilling. Much care was taken to ensure that the DCSM would be sufficiently rigid, with mounting points for struts to stabilize the Drill and BHIS masts. Electrical wiring was routed throughout the structure to provide power and data communications.

\subsection{Remote Operations and Automation Subsystem}

The goals of the Remote Operations and Automation subsystem were twofold. The first goal was to provide data communications between the borehole and the science operation centers over a remote satellite link. Daily activity requests were sent to the personnel at the borehole operating the equipment. After executing the plan, the resulting science and operations data was transferred back to the science centers. This was all to be accomplished in a way that "simulated" a real mission from the scientists' perspective. The second goal was to automate the borehole equipment in order to ease the overall complexity of operations, and to prove out automation software technologies for a drilling mission. This part of the system was not required to simulate a real mission in that there would be on site engineers at the borehole assisting in the operation, maintenance, and troubleshooting of equipment. In general, most of the onboard equipment operations were automated for nominal operation. However, human intervention was allowed to handle faults as they occurred, handle non-automated equipment (eg. ATP luminometer), and to provide non-mission support such as cleaning and contamination control. 
The normal flow of operations was designed to occur as follows:

1) The science team provided the operations team with the day's science plan. The plan consisted of multiple decisions regarding drilling, borehole inspection, core subsampling, and generation of remote science data.

a) Scientists decided whether to drill or use the BHIS. Only one of these could have access to the hole at a time. If drilling, a maximum depth to achieve could be specified. If using the BHIS, scientists could request where in the hole to take images and where to take Raman measurements.

b) Scientists decided which cores to keep and which to eject. The scientists had to be judicious about how long to hold on to cores. They needed to make sure they had all of the data they needed from the core, but at the same time, make room for additional cores to be generated and stored.

c) Scientists could request additional RSI measurements. In general, the RSI data was automatically uplinked to the science centers immediately after processing. However, the scientists could request re-measurements if there were problems with the data. In addition, the hyper-spectral imaging data was too large to transmit for every core. Therefore the scientists requested averaged spectral data for small subsections of each core.

2) The mission operations lead (located at the borehole) examined the plan to determine whether or not it was feasible given the status and capabilities of the equipment. If there were any problems, the plan was rejected, and follow up discussions occurred with the science team in a way that was mission-like. In general this involved negotiating what could reasonably be accomplished in a day.

3) After accepting the plan, it was then translated into machine readable sub-plans. These plans were then executed via the onboard automation equipment.

4) The science and operations data generated from executing the plans was then uploaded to a server, and made available to the science team via a MARTE Science Data browser web form.

5) After examining the data, the science team would plan the next day's activities.

Figure 18 shows the software architecture for the onboard automation software at the borehole. To simplify the data communications architecture, we took a centralized approach to command and data handling. That is, all commands to each subsystem came only from the Executive (except in the case of human intervention). All data transmitted to the mission operations center was transmitted through the telemetry server at the request of the Executive. The subsystems only needed to communicate with the Executive and the Telemetry Server. There was no communications between the subsystems themselves.

In this architecture, the Executive loaded a plan file, and then executed actions specified in the plan file. The plan files were created by engineers in the field based on the requests that were made by the scientists in the web form. The actions in the plan file were executed by sending commands to the Mars Instrument Interface (MInI) dispatcher. MInI is a communications package that utilizes the Common Object Request Brokering Architecture (CORBA) for transferring data between clients and servers. The MInI Dispatcher relayed the commands from the Executive to the appropriate 
subsystem Server. The servers in turn caused the commands to be executed by calling appropriate routines in the subsystem control software.

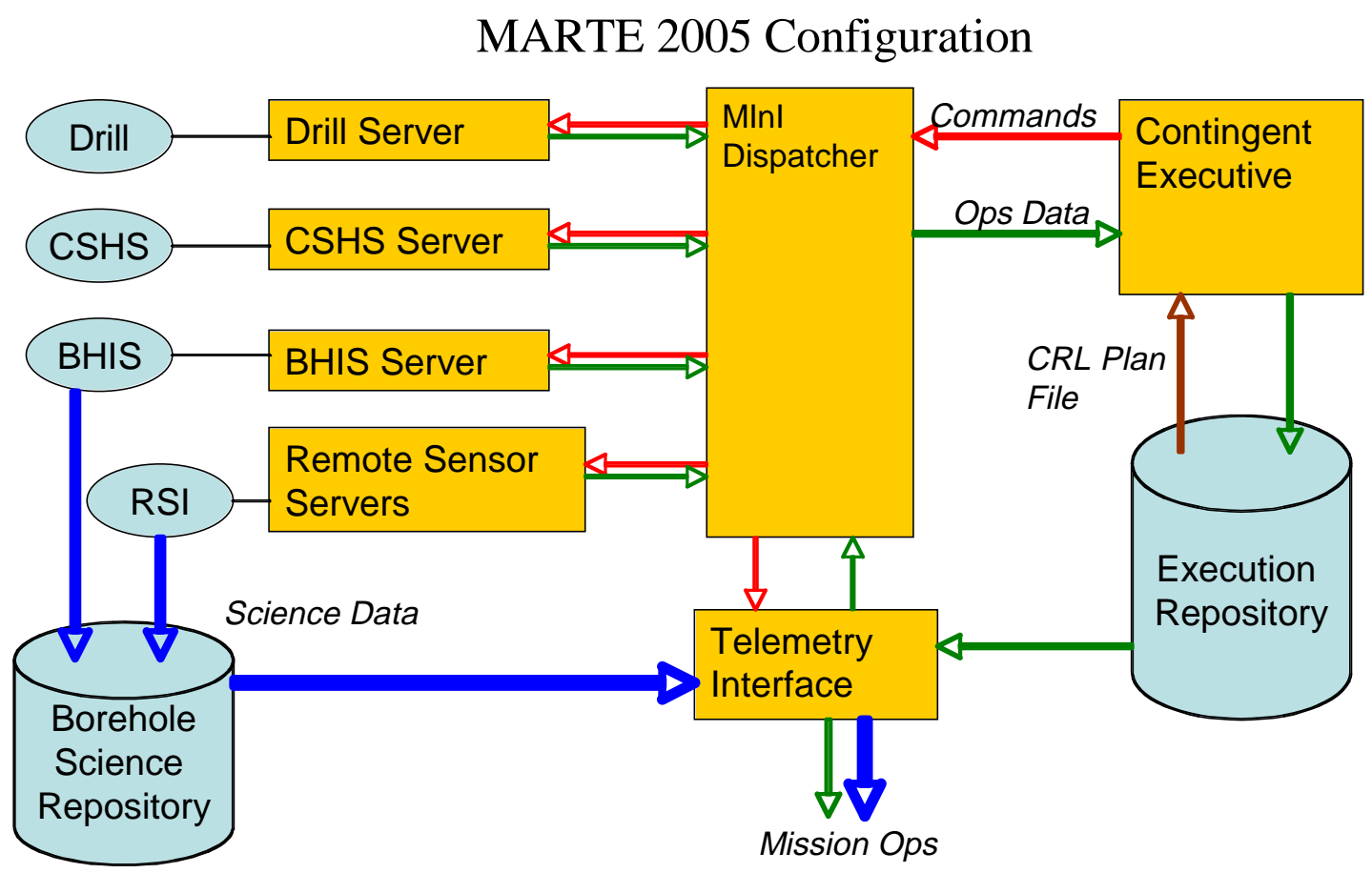

Figure 18: Onboard automation software architecture. The Executive controls all the instruments by transmitting commands through the MInI Dispatcher. The resulting science data is transmitted to Mission Ops via the Telemetry Interface.

The Executive is based on the Contingent Rover Language (CRL). The CRL Executive has a long history of use onboard NASA Ames and JPL rovers (Bresina et al., 1999; Pedersen et al., 2003). In 2003 the CRL Executive was upgraded to improve robustness, provide the ability to execute concurrent actions, and reason about uncertain state estimates. It was tested extensively and demonstrated during the NASA Ames' K9 rover field tests in 2003 and 2004. For the MARTE field test, the CRL Executive proved to be effective and robust. Since the MARTE system did not include onboard diagnostics, it was necessary at times for the human operators to detect and remediate system hardware failures. To enable this capability, the CRL Executive was enhanced to allow operator intervention followed by seamless continuation of plan execution. A sister project called the "Drilling Automation for Mars Exploration (DAME)" project incorporated diagnostic systems into this architecture to monitor the drilling activity. In the DAME project, the CRL executive responded to the faults by executing recovery plans (Glass et al., 2006). 


\section{Field Test Results:}

The MARTE team deployed the entire system for two field tests. The first occurred in the Bonny Doon quarry near Santa Cruz, California in June of 2005. The goals of the test at Bonny Doon were to investigate logistics and setup issues, debug the hardware and software, and to investigate needed changes prior to a deployment overseas. The material drilled consisted primarily of soft limestone. This site was selected for the ease of drilling operations and the proximity to Ames Research Center where the system integration took place. After four days of drilling, the system was able to reach 1.3 meters of depth. This fell considerably short of the requirement for the mission simulation where we were targeting 0.5 meters per day. Part of the problem was related to unseasonable rains in the region which caused logistical problems and delays. In addition, we found that it was relatively easy to drill through the top layer of consolidated limestone. However, once we hit unconsolidated material, the drilling slowed down significantly. This was alleviated by using compressed air to assist in blowing out the cuttings. In addition, there were many weaknesses in the automated equipment at that point in time, resulting in significant down time. Overall, even though the drill failed to reach its depth target (2 meters), many valuable lessons were learned and problems resolved which paved the way for the mission simulation at Peña del Hierro.

The mission simulation took place at an abandoned mine site near the small town of Minas de Riotinto in southwestern Spain, in September of 2005. The mission simulation spanned one month. Two science teams participated in the experiment. The first team, located in Madrid, Spain, controlled the first two weeks of operations and science activities. The second team located at NASA Ames Research Center was in charge during the last two weeks. The materials drilled through included a weak soil composed of red clays, acidic volcanic tuff, and gossanized acidic volcanic tuff alternating with clays. The success criteria for the mission included drilling to a minimum 5 meters of depth, obtain sufficient core data to describe the geologic formation, and obtain at least one positive and substantiated life detection signature.

The mission simulation was a huge success in that all objectives and success criteria were met or exceeded. In 21 days, we were able to drill a total of 43 hours. The rest of the time was spent in moving up and down the hole, transferring the core, working with the BHIS, dealing with logistics, conducting contamination control, and/or recovering from problems. The drill reached a total depth of 6.1 meters, resulting in an average penetration rate of 0.14 meters per hour of operation. Figure 19 shows a summary of the ROP, auger power, and core recovery versus depth for each of the materials encountered. More detailed analysis of the lithology is described in Bonaccorsi et al., 2007. 

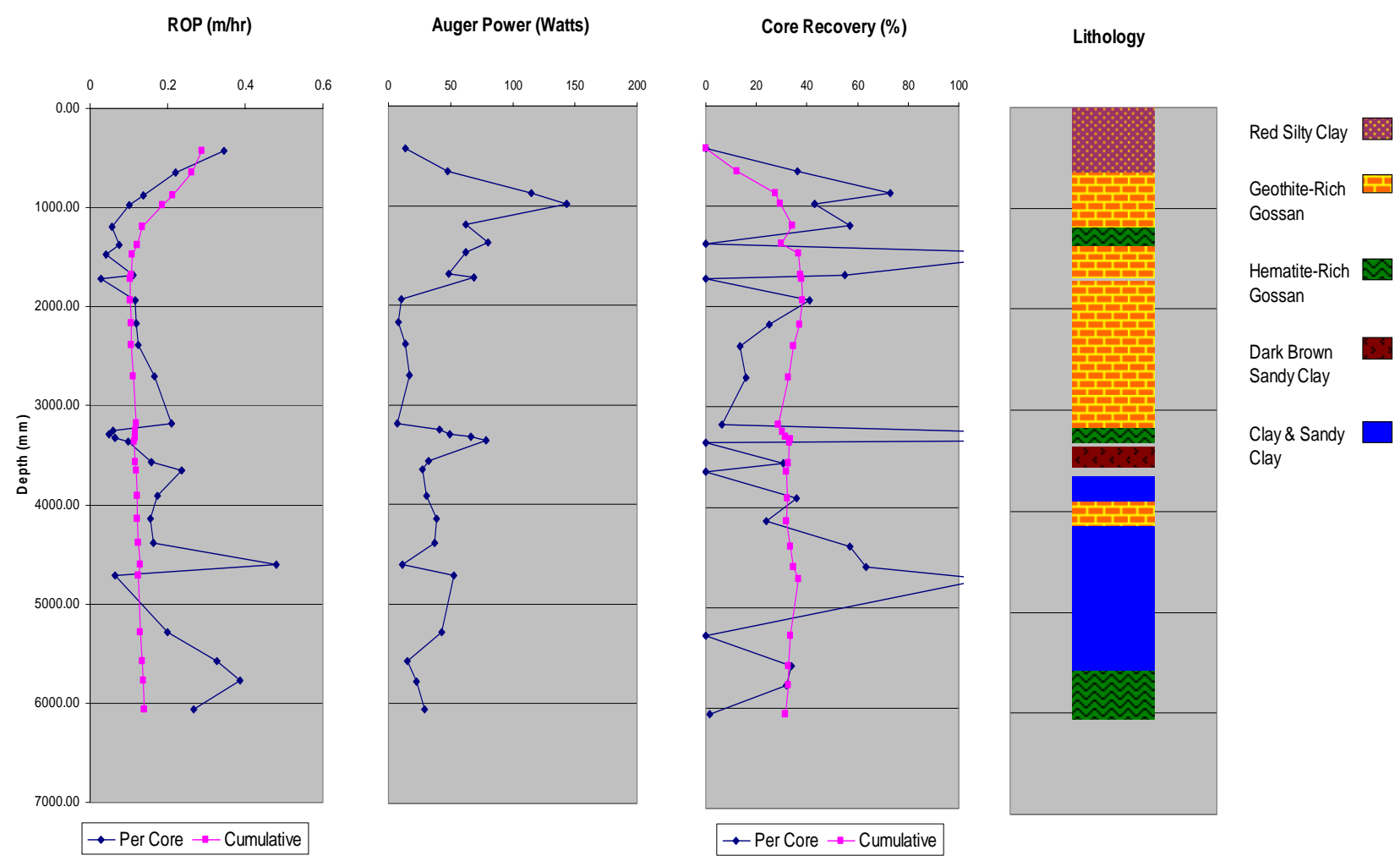

Figure 19 - Drill performance versus material type. The graphs show Rate of Penetration, Auger Power, and Core Recovery. After 1.7 meters, compressed air was used to help flush the cuttings away from the drill bit.

At the beginning of the mission, the rate of drill penetration was relatively high. But as depth increased, the power increased rapidly, causing the control to reduce the penetration rate. This trend was most likely due to an inability to effectively clear the cuttings away from the drill bit. A notable improvement in power and rate of penetration occurred at 1.7 meters. This is where the compressed gas was used to help flush the cuttings from the hole while drilling.

Core recovery throughout the mission was relatively poor, retrieving only $31 \%$ of the core on average (1.9 meters). A total of 29 cores were retrieved. Science data was generated for each core, and BHIS data was collected, resulting in a total of $2 \mathrm{~GB}$ of data. The breakout for this data is shown in Table 1. 


\begin{tabular}{|l|l|}
\hline Data Type & MegaBytes (MB) of Data \\
\hline Panoramic Camera & 37.1 \\
\hline Microscopic Camera & 358.7 \\
\hline VNIR Spectrometer & 72.0 \\
\hline Hyper-spectral Data & 1417.0 \\
\hline ATP Luminometer & 0.0 \\
\hline Signs of Life Detector & 119.7 \\
\hline Bore Hole Inspection System & 61.3 \\
\hline
\end{tabular}

Table 1- Amount of data generated by each instrument type.

The science teams were able to use this data to successfully characterize the geology of the material we were drilling through. Figure 20 shows the lithology record. Note how the BHIS data was used to fill in areas where there was no core recovery. Figure 21 shows a microscopic image that was taken of core 21. The images combined with spectral information helped identify the various mineral compositions.

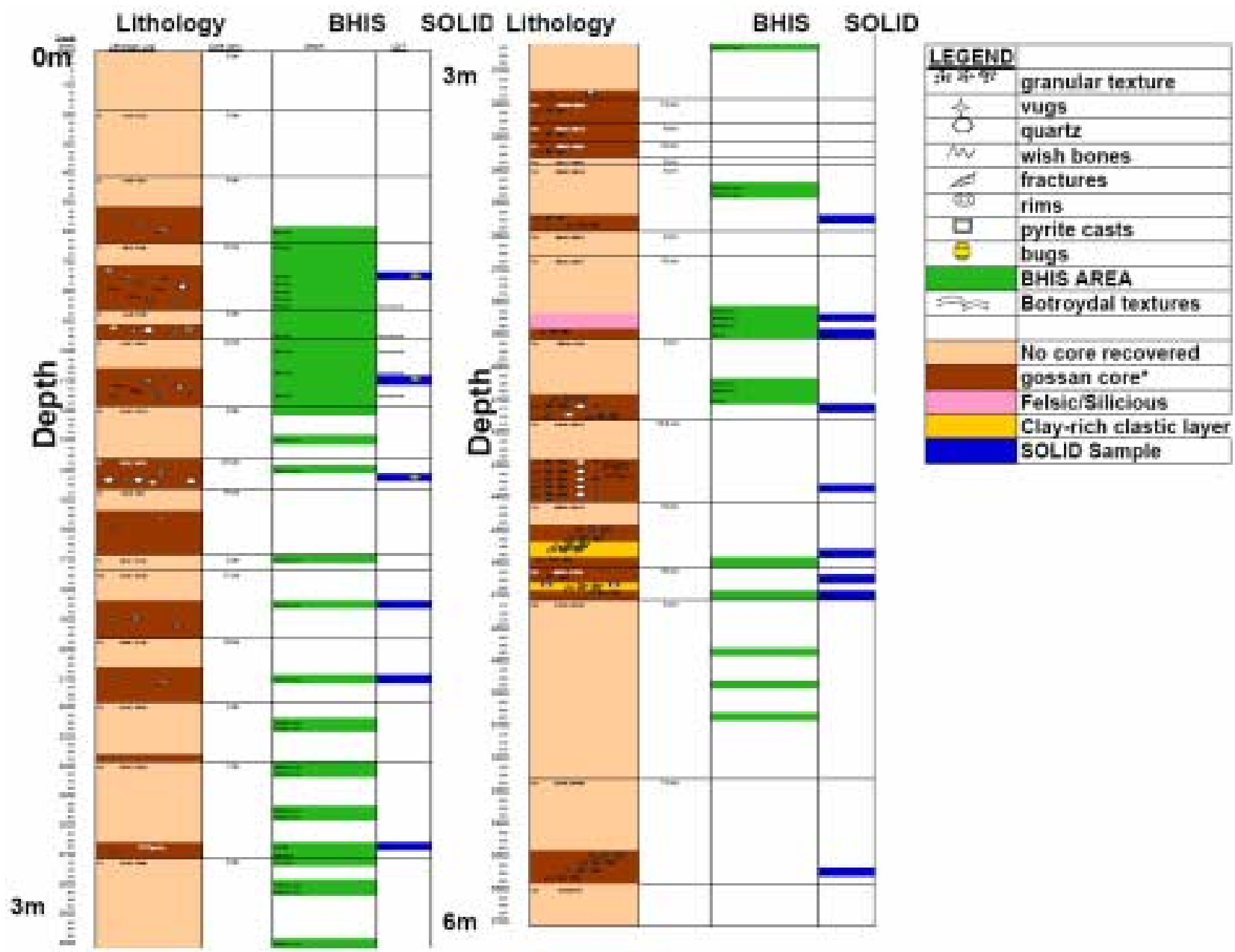

Figure 20 - Lithology versus depth characterized by science team. Dark brown corresponds to core results, green shows depths imaged by the BHIS, and Blue shows where life detection samples were taken. 


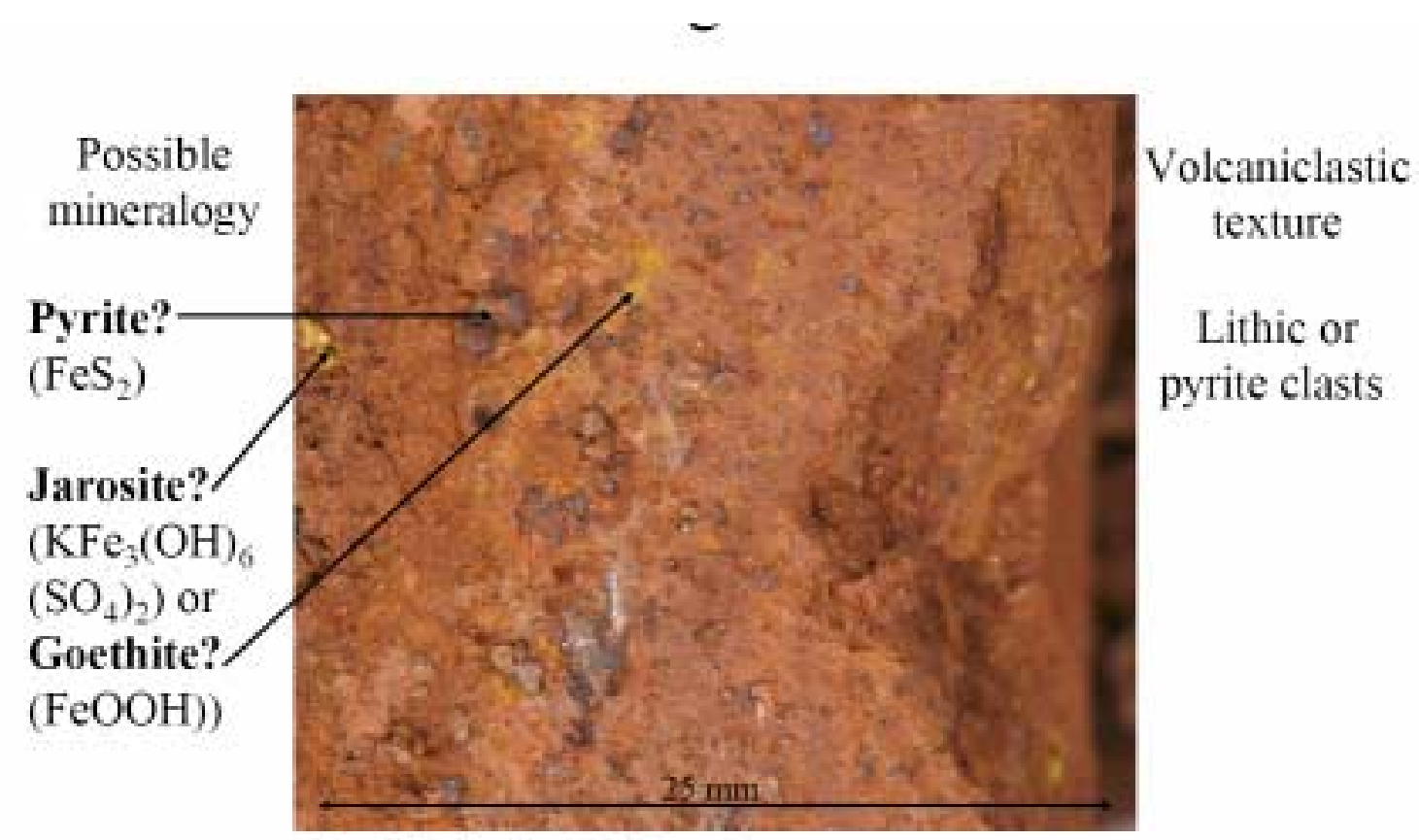

Core 21 (depth $-3908 \mathrm{~mm}$ )

Figure 21 - Microscopic image providing understanding of material composition.

The science team requested a total of fifteen life detection samples, at depths ranging from $650 \mathrm{~cm}$ to $5577 \mathrm{~cm}$. Preliminary analysis during the mission showed positive life detection signatures in three of the samples. More extensive analysis after the mission and comparison with laboratory control experiments showed that positive biosignature markers were actually present in twelve of the samples (Parro 2007). This success rate illustrates the power of pre-screening candidate locations for subsampling using the remote sensing instruments.

\section{Lessons Learned:}

This section describes some of the primary technology lessons learned from our experiences in designing, developing, and testing the equipment.

1) There is still a significant debate regarding the best means for obtaining science data in a drilling mission scenario. Some of the options we looked at included:

- Retrieval and analysis of drill cuttings

- Retrieval of cores to the surface

- Using downhole probes or instruments embedded in the drill shaft

Ultimately we rejected using the cuttings because of the inability to pinpoint where the cuttings were generated, the possibility of diluting a positive biomarker, and cross contamination. During testing we found that coring and use of the downhole probe were complimentary, because there were many places where we had poor core recovery. The use of the probe helped fill in some of the missing pieces of geologic information. 
2) A potential optimization of the coring approach would be to use selective coring instead of continuous coring. During the design phase, we decided that we wanted a complete core record for scientific analysis. However, this requires that the drill be retrieved after every $25 \mathrm{~cm}$, just in case the core barrel filled up. Every time a core was retrieved, the drilling process was suspended for significant lengths of time, and every operation in the process (core break, drill segment attach/detach, core transfer) represented a potential failure mode. To minimize this, an alternative strategy could have been to let the scientists selectively decide when to take a core. Then the drill bit could stay in the ground longer to make faster progress.

3) During drilling, we learned that by flushing the cuttings out of the hole with air, we could make substantially faster progress. However, the downside of this was that much of the core was lost in the process when drilling through weakly consolidated or porous materials. Towards the end of the mission, we attempted blowing air down the hole while drilling the first $15 \mathrm{~cm}$ of depth, and then turned the air off for the last $10 \mathrm{~cm}$. This provided us with some success in retrieving at least a portion of core for every $25 \mathrm{~cm}$ interval. This also points to a degree of flexibility that potentially would be useful for an actual Mars drilling mission.

4) It would be desirable to obtain significantly higher core recovery. There are several reasons for the poor core recovery obtained. First, the material was highly fractured and porous. Second, the blowing of air into the core area actually exacerbated the problem, sometimes forcing the trapped core material out of the core tube. The design was implemented in such a way that we knew this could be problematic. There was no means to positively prevent the core from falling out of the end. The design depended on two small keys and friction to lock the core in place. For a Mars mission where the material is likely to be unconsolidated, a more positive means of preventing core loss would be required.

5) Contamination control is a significant issue that will need to be addressed (Miller et al., 2007). Originally we considered this to be primarily a problem for the experiment but not for a real Mars mission. The experiment had contaminants from the surface, human contact, and equipment that had to be prevented from getting into the sample. For a Mars mission, these sources of contamination would not exist. Consequently, during the experiment we dedicated a lot of hands on effort to ensuring the equipment was clean and sterilized prior to coming into contact with core sample. However, the tests also pointed out that many of the CSHS operations generated dust, which could cause cross-contamination. Most of the dust comes from the sawing operations, but the crusher also produced more dust than expected. Methods need to be devised that contain and dispose of the dust generated by these processes. Likewise, the devices need to be refined to eliminate dust traps (e.g. corners) that would cause cross contamination.

6) This experiment proved the utility of a suite of pre-screening instruments to ensure the most effective use of limited measurement assets such as reactive bio-assay elements. While the information generated by such instruments can be high bandwidth and adds operational complexity, it contributes considerably to the total scientific product of the mission and greatly improves the likelihood of successful bio-assay measurements.

7) With respect to the borehole inspection, we learned that the image capture system must be capable of operating in adverse situations (i.e. poor lighting, high borehole surface relief, variable or specular reflectance, etc.) Significant effort was expended during the mission to get the images clear and in focus. Potentially this could be improved by using a lens with a longer focal length, a better illumination system, and/or improved autonomous focusing capability. 
8) Another issue with borehole inspection was that many of the down hole images looked very similar, and it was difficult to see the surface texture. We believe this can be attributed to the cuttings and dust being smeared on the borehole wall. We saw a similar effect on the cores, such that you couldn't see the structure unless you shaved off the top surface. For a future mission, this is a technical difficulty that will need to be overcome, perhaps by grinding a spot on the borehole wall prior to imaging.

9) For the onboard automation software, insight was gained regarding the level of autonomy required. Although the CRL Executive permits plans to have embedded contingent branches, this feature was not used because there was a human in the loop to make decisions about what to do based on the current state of the system. Instead, plan files were created to implement a particular functionality, and then the onsite human decision maker decided when it was appropriate to upload each plan. This approach and our results lead to several observations regarding onboard execution systems for drilling:

a. Most drilling and core processing operations can be specified as a sequential or concurrent set of sequential tasks. Therefore a procedural based language such as CRL is appropriate for this type of mission.

b. In a fully automated system, it would be desirable to enable contingent operation because of the enormous amount of uncertainty. For instance, the amount of time that it takes to drill a single core is highly variable and unpredictable. Branches utilizing temporal and resource constraints would allow the system to selectively choose its next operation based on the state of the system, time, and resources available. Table 2 shows some examples of contingencies based on our experience in the field.

c. An onboard planner is probably not necessary because most of the sequences are well defined as evidenced by our ability to operate with only a few pre-defined plans. However, an off-board planner might be useful in specifying the contingencies mentioned above.

\begin{tabular}{|c|c|}
\hline Condition & Action \\
\hline $\begin{array}{l}\text { Time of Day less than X1 or Energy } \\
\text { remaining less than Y1. }\end{array}$ & Stop drilling and transmit data. \\
\hline $\begin{array}{l}\text { Ready to re-enter ground, and Time of } \\
\text { Day less than X2 or Energy remaining } \\
\text { less than Y2. }\end{array}$ & $\begin{array}{l}\text { Subsample core or use BHIS for } \\
\text { remaining time/ energy. }\end{array}$ \\
\hline Core clamp is empty & Bypass core processing. \\
\hline $\begin{array}{l}\text { Drill raised and detected that core } \\
\text { length is less than } \mathrm{Z} 1\end{array}$ & $\begin{array}{l}\text { Bypass handoff to core clamp and return } \\
\text { to drilling. }\end{array}$ \\
\hline Subsample not retrieved. & Bypass crushing. \\
\hline $\begin{array}{l}\text { BHIS panoramic images not all in } \\
\text { focus. }\end{array}$ & $\begin{array}{l}\text { BHIS is either not centered or the hole is } \\
\text { not concentric. Use auto focus for } \\
\text { portions of image. }\end{array}$ \\
\hline
\end{tabular}

Table 2: Useful automation contingencies for an actual Mars drilling mission. 


\section{Conclusions:}

The Mars Astrobiology Research and Technology Experiment (MARTE) was a complex, three year, international project looking at science and technologies needed for a future drilling mission to Mars. This type of mission will be essential to discovering whether life ever existed, or even perhaps exists today in the subsurface of the planet. The MARTE experiment completed all of its major science and technology goals. Ultimately the team fielded a month long mission simulation where teams of remote scientists dictated the operation of semi-automated drilling, core processing, and life detection instruments, and analyzed the resulting science data. The mission simulation met or exceeded all success criteria: the drill reached over 6 meters of depth, 28 cores were processed generating 2 Gigabytes of scientific data, and the science teams correctly interpreted the mineralogy and detected biosignatures in 12 core samples. This demonstration and resulting lessons learned will help to pave the way for a future Mars drilling mission.

\section{Acknowledgements:}

MARTE was jointly funded by the NASA Astrobiology Science and Technology for Exploring Planets (ASTEP) program through NRA 02-OSS-01. Partial funding for automation was provided by the NASA Intelligent Systems program. Spanish participation in MARTE was funded by the Centro de Astrobiología. We gratefully acknowledge the hard work and dedication of all of the MARTE team members at NASA Ames Research Center, NASA Johnson Space Center, Honeybee Robotics, University of Oklahoma, Portland State University, and the Centro de Astrobiología. We also thank the Museo Minero de Rio Tinto, Spain and the staff of the Vazquez Díaz Hotel in Nerva, Spain for providing field facilities and logistical support to the MARTE project.

\section{References:}

Arvidson, R. E., et al. (1998). Rocky 7 prototype Mars rover field geology experiments: 1. Lavic Lake and Sunshine Volcanic Field, CA, J. Geophys. Res., 103, 22,671-22,688.

Arvidson, R. E., Squyres, S., Baumgartner, E., Dorsky, L., and Schenker, P. (2000) Rover trials for Mars Sample Return mission prove successful, Eos Trans. AGU, 81, 65.

Bonaccorsi, R., Stoker, C.R., and Sutter, B (2007) Characterization of the MARTE Rio Tinto samples and Ground Truth for Remote Science Observations. Astrobiology, submitted for special issue on MARTE Project.

Bresina, J. L. and Golden, K. and Smith, D. E. and Washington, R., (1999). Increased flexibility and robustness of Mars rovers. Proceedings of i-SAIRAS '99, The 5th International Symposium on Artificial Intelligence, Robotics and Automation in Space.

Cabrol, N., Chong-Diaz, G., Stoker, C. et al. (2001a). Nomad rover field experiment, Atacama Desert, Chile, 1. Science results overview. J. Geophys. Res., 106, 7785-7806.

Cabrol, N., Bettis III, E., Glenister, B. et al. (2001b) Nomad rover field experiment, Atacama Desert, Chile, 2. Identification of paleolife evidence using a robotic vehicle: lessons and recommendations for a Mars sample return mission, J. Geophys. Res., 106, 7807-7815. 
Christian, D., Wettergreen, D., Bualat, M., Schwer, K., Tucker,D. and Zbinden,E. (1997). Field experiments with the Ames Marsokhod rover. 1997 Field and Service Robotics Conference, pp. 93-100, Australian Robotics and Autonomy Assoc., Canberra, Australia.

Des Marais, D.J., Allamandola, L.J., Benner, S.A., Boss, A.P., Deamer, D., Falkowski, P.G., Farmer, J.D., Hedges, S.B., Jakosky, B.M., Knoll, A.H., Liskowsky, D.R., Meadows, V.S., Meyer, M.A., Pilcher, C.B., Nealson, K.H., Spormann, A.M., Trent, J.D., Turner, W.W., Woolf, N.J., and Yorke, H.W. (2003) The NASA Astrobiology Roadmap. Astrobiology 3(2), pp. 219-235.

Fairén A. G., et al., (2004). Inhibition of carbonate synthesis in acidic oceans on early Mars. Nature, 431, 423- 426.

Fisher, J., Antoniades, J.A., Rollins,C., Xiang, L. (1998). Hyperspectral imaging sensor for the coastal environment. International Optical Design Conference 1998, L. R. Gardner and K. P. Thompson, eds., Proc. SPIE 3482, 179-186.

Glass, B., Cannon, H., Branson, M., Hanagud, S. and Paulsen, G., (2006). DAME: PlanetaryPrototype Drilling Automation. Proc. AIAA Space 2006, San Jose, CA.

Hansen, C.J., Bearman, G., Furstenau, S., Horn, J., Mahoney, C., Patrick, S., Peters, G., Scherbenski, J., Shiraishi, L., Zimmerman, W. (2007) SPADE: A rock crushing and sample handling system developed for Mars missions. Journal of Geophysical Research - Planets, (in press).

Gómez-Elvira, J., Martín, J., Rodríguez,J.A., Romeral, J., Sebastián, E., Torres, J. (2004). A logging instrument for subsurface planetary exploration. AbSciCon Moffett Field, California.

LeGrand, R., Machulis,K., Miller,D.P., Sargent,R., Wright,A. (2005). The XBC: a modern lowcost mobile robot controller. In Proceedings of IROS 2005. IEEE Press.

Miller, D.P., Desai, R.S., Gat, E., Ivlev,R., Loch, J. (1992) Reactive navigation through rough terrain: Experimental results. In Proceedings of the 1992 National Conference on Artificial Intelligence, pages 823-828, San Jose, CA. AAAI.

Miller, D.P., Bonaccorsi, R., and Davis, K. (2007) Design and practices for use of automated drilling and sample handling in MARTE while minimizing terrestrial and cross contamination. Astrobiology (submitted, MARTE Project special issue.)

Parro, V., Rodríguez-Manfredi, J.A., Briones, C., Compostizo, C., Herrero, P.L., Vez, E., Sebastián, E., Moreno-Paz, M., García-Villadangos, M., Fernández-Calvo, P., González-Toril, E., Pérez-Mercader, J., Fernández-Remolar, D.C., and Gómez-Elvira, J. (2005) Instrument development to search for biomarkers on mars: Terrestrial acidophile, iron-powered chemolithoautotrophic communities as model systems. Planetary and Space Science 53, pp. 729-737.

Parro, V., Fernández-Calvo, P., Rodríguez Manfredi, J.A., Moreno-Paz, M., Rivas, L.A., GarcíaVilladangos, M., Bonaccorsi, R., González-Pastor, J.E., Prieto-Ballesteros, O., Schuerger, A., Davidson, M., Gómez-Elvira, J., and Stoker, C.R. (2007) SOLID2: An antibody array-based life detector instrument in a Mars drilling simulation Experiment (MARTE). Astrobiology (submitted, MARTE Project special issue.) 
Paulsen, G., Zacny, K., Chu, P., Mumm, E., Davis, K., Frader-Thompson, S., Cannon, H., Glass, B. (2006). Robotic Drill Systems for Planetary Exploration. Proc. AIAA Space 2006, San Jose, CA.

Pederson, L., Bualat, M., Smith, D.E., Washington, R., (2003) Integrated Demonstration of Instrument Placement, Robust Execution and Contingent Planning. International Symposium on Arti $\urcorner$ cial Intelligence and Robotics in Space (i-SAIRAS), Nara, Japan.

Rickard, Lee J.; Basedow, Robert W.; Zalewski, Edward F.; Silverglate, Peter R.; Landers, Mark, (1937). HYDICE: an airborne system for hyperspectral imaging. Proc. SPIE Vol. 1937, p. 173-179, Imaging Spectrometry of the Terrestrial Environment.

Squyres, S., et al.(2004). In situ evidence for an ancient aqueous environment at Meridiani Planum, Mars. Science, 306, 1709-1714.

Stoker, C.R., N. Cabrol, T. Roush, J. Moersch, et al., (2001). The 1999 Marsokhod Rover Mission Simulation at Silver Lake California: Mission overview, data sets, and summary of results, J. Geophys. Res., 106, 7639-7664.

Stoker, C.R., T. L. Roush, R. E. Arvidson, J.L. Bresina, M.G. Bualat, L.J. Edwards, L.J. Flueckiger, R.M. Washington, L.A. Nguyen, H. Thomas, and A.R. Wright. (2002). Two dogs, new tricks, a two-rover mission simulation using K9 and FIDO at Black Rock Summit, Nevada, J. Geophys. Res. 107, E11, 8009,doi:10.1029/2000JE001490.

Stoker, C.R. L.G. Lemke et al. (2004). Mars Analog Río Tinto Experiment (MARTE): 2003 drilling campaign to search for a subsurface biosphere at Río Tinto, Spain. 35th LPSC, Abstract 2025, Houston, TX.

Stoker, C.R., T. Stevens, R. Amils, J. Gomez-Elvira, N. Rodriguez, F. Gomez, E. Gonzales-Toril, A. Aguilera, D. Fernandez-Remolar, S. Dunagan, L.G. Lemke, J. Zavaleta, and J.L. Sanz (2005), Characterization of a subsurface biosphere in a massive sulfide deposit at Rio Tinto, Spain: implications for extant life on Mars. 36th LPSC, Abstract 1534, Houston, TX.

Stoker, C., Cannon, H., Dunagan, S., Lemke L., Glass, B., Miller, D., Gomez-Elvira, J., Davis, K., Zavaleta, J., Winterholler, A., Roman, M., Rodriguez-Manfredi, A., Bonaccorsi, R., Bell, M.S., Brown, A., Battler, M., Chen, B., Cooper, G., Davidson, M., Fernandez-Remolar, D., Gonzales-Pastor, E., Heldmann, J., Martinez-Frias, J., Parro, V., Preto-Ballesteros, O., Sutter, B., Schuerger, A., Schutt, J. (2007). The 2005 MARTE Robotic Drilling Experiment in Rio Tinto Spain: Objectives, Approach, and Results of a Simulated Mission to Search for Life in the Martian Subsurface. Astrobiology (submitted, MARTE Project special issue.)

Volpe, R., Baumgartner, E., Schenker, P., Hayati, S. (2000). Technology development and testing for enhanced mars rover sample return operations. In Proceedings of the IEEE Aerospace Conference.

Winterholler,A., Roman, M., Miller,D.P., Krause,J., Hunt,T. (2005) Automated core sample handling for future mars drill missions. In iSAIRAS 2005, Munich Germany. 